\title{
Source Rupture Process of the 2004 Chuetsu, Mid-Niigata Prefecture, Japan, Earthquake Inferred from Waveform Inversion with Dense Strong-Motion Data
}

\section{$\operatorname{AUTHOR}(\mathrm{S})$ :}

Asano, Kimiyuki; Iwata, Tomotaka

\section{CITATION:}

Asano, Kimiyuki ... [et al]. Source Rupture Process of the 2004 Chuetsu, Mid-Niigata Prefecture, Japan, Earthquake Inferred from Waveform Inversion with Dense StrongMotion Data. Bulletin of the Seismological Society of America 2009, 99(1): 123-140

\section{ISSUE DATE:}

2009-02-01

URL:

http://hdl.handle.net/2433/209746

\section{RIGHT:}

This copy is for distribution only by the authors of the article and their institutions in accordance with the Open Access Policy of the Seismological Society of America. 


\section{Bulletin of the Seismological Society of America}

This copy is for distribution only by

the authors of the article and their institutions in accordance with the Open Access Policy of the Seismological Society of America.

For more information see the publications section of the SSA website at www.seismosoc.org

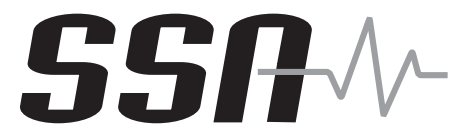

The Seismological Society of America

400 Evelyn Ave., Suite 201

Albany, CA 94706-1375

(510) 525-5474; FAX (510) 525-7204

www.seismosoc.org 


\title{
Source Rupture Process of the 2004 Chuetsu, Mid-Niigata Prefecture, Japan, Earthquake Inferred from Waveform Inversion with Dense Strong-Motion Data
}

\author{
by Kimiyuki Asano and Tomotaka Iwata
}

\begin{abstract}
The kinematic source rupture process of the 2004 Chuetsu, mid-Niigata prefecture, Japan, earthquake, is estimated from strong-motion data by the linear waveform inversion method. In order to develop appropriate Green's functions, onedimensional velocity structure models for each station are constructed by modeling the aftershock waveforms. The estimated top of the bedrock is deeper at the western side of the fault and relatively shallow at the eastern side. This tendency coincides with other investigations of seismic tomography and microtremor array observations. The obtained source model shows large slips in the vicinity of the hypocenter. The reverse slipping rupture originated from the deeper part of the fault and propagated toward the up-dip and southwest directions. The near-surface slip is small. Two tests are demonstrated to check the stability of the obtained source model. The first test examines the effects of the number of available stations on the solution, and the second test examines how the difference in the target waveform type affects the solution. The number of stations affects the variation of slip amount, and more than 12 stations appear to be sufficient to obtain a stable solution in this case. The difference in the target wave type in the data set does not significantly affect the solution if the number of stations is sufficient and the Green's functions are well calibrated. The model obtained using calibrated velocity structure models shows clear image of high-slip area compared to the model obtained using a single velocity structure model.
\end{abstract}

\section{Introduction}

At 1756 Japan Standard Time (JST) (0856 coordinated universal time [UTC]) on 23 October 2004, a large shallow inland earthquake occurred in the Chuetsu district of the midNiigata prefecture, central Japan (Fig. 1). The Japan Meteorological Agency (JMA) estimated that the magnitude of this earthquake was 6.8. This earthquake is a shallow crustal earthquake with reverse faulting. The strike, dip, and rake angles obtained from the moment tensor solution released by the F-net Broadband Seismograph Network, which is operated by the National Research Institute for Earth Science and Disaster Prevention (NIED), Japan, are $212^{\circ}, 47^{\circ}$, and $93^{\circ}$, respectively (see Data and Resources section). The result of the field surveys revealed minor surface cracks and deformations resulting from this earthquake (e.g., Kim and Okada, 2005).

The 2004 Chuetsu earthquake occurred in an active fault and folding mountain system. The faulting and folding structures were originally formed at 25-20 Ma as normal faults during the backarc rifting associated with the opening of the Japan Sea. The structures were subsequently reactivated as reverse faults by the tectonic inversion due to the increase in the velocity of the westward motion of the subducting Pacific plate from 3.5 Ma (Sato, 1994). Because of these tectonic settings, the sedimentary layers in this area are significantly thick and their thickness varies spatially. Several authors have carried out temporary aftershock observations and precise investigations of the hypocenter relocation by considering the complex velocity structure (Kato et al., 2005; Okada et al., 2005; Shibutani et al., 2005). Their studies revealed that the expected location of the hypocenter of the mainshock is approximately $3-4 \mathrm{~km}$ northwest from the hypocenter routinely located by the JMA using a uniform velocity structure model. The three-dimensional velocity structure models obtained from the double-difference tomography method (e.g., Kato et al., 2006; Okada et al., 2006) suggest that the thickness of the low-velocity layers is considerably greater at the northwest side of the fault area than at the southeast side. These studies imaged the highangle westward-dipping fault plane as a zone of velocity change from a high velocity at the footwall side to a low velocity at the hanging-wall side. 


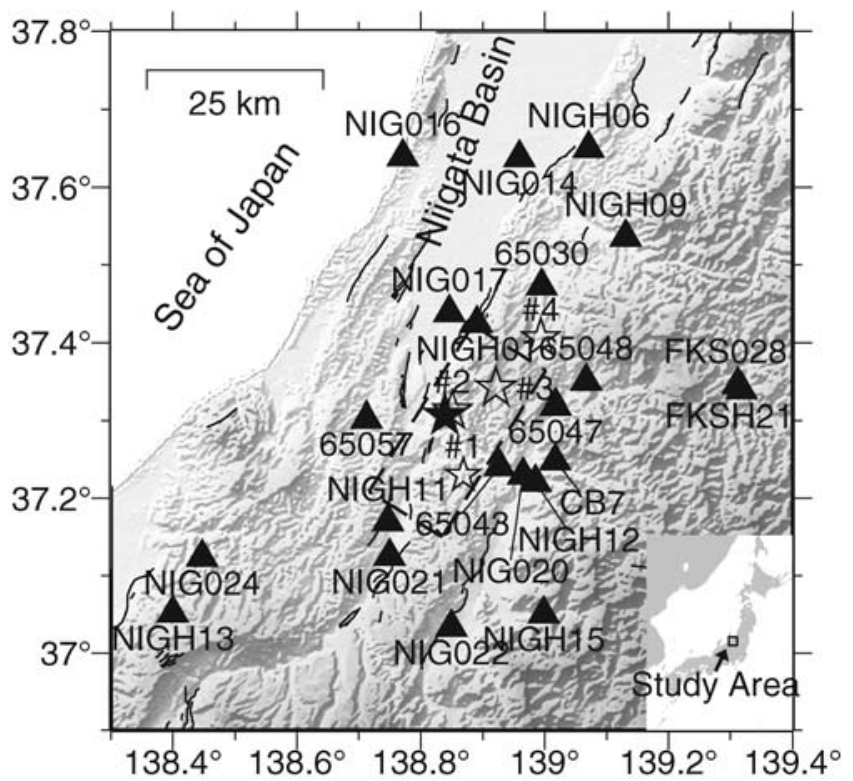

Figure 1. Map showing the study area. The solid star indicates the epicenter of the mainshock. The broken rectangle shows the surface projection of the fault plane of the mainshock assumed in the inversion analysis. The open stars represent the epicenters of the aftershocks used in the velocity structure modeling. The solid triangles indicate the strong-motion stations used in this study. The solid lines show the surface traces of active faults compiled by Nakata and Imaizumi (2002).

The ground motions from the 2004 Chuetsu earthquake sequence were densely observed by K-NET (Kinoshita, 1998) and KiK-net (Aoi et al., 2000) stations in and around the epicentral area. JMA and local governments also obtained time histories of ground motions by their seismic intensity observation network. Among these stations, several strongmotion stations recorded extremely large ground motions with peak ground acceleration greater than $1000 \mathrm{~cm} / \mathrm{sec}^{2}$ or peak ground velocity greater than $100 \mathrm{~cm} / \mathrm{sec}$ (e.g., Mori and Somerville, 2006). For understanding the physical mechanism of the ground-motion generation process during this earthquake, a reliable and detailed source model needs to be constructed. In general, the thick and complicated sediment structure would also influence the wave propagation and amplification characteristics during the earthquake. If inadequate velocity structure models are used in the source inversion, the obtained source model might be affected by the inaccuracy in the Green's functions because observed ground motion is a convolution of source, propagation path, and site effects. Therefore, it is quite necessary to use appropriate velocity structure models in calculating Green's functions for retrieving a reliable source model from the observed groundmotion data.

In the last two or three decades, waveform inversion techniques utilizing near-source strong motions to estimate the spatial and temporal kinematic slip history on the source fault during an earthquake have been widely applied for many remarkable earthquakes (e.g., Hartzell and Heaton,
1983; Asano et al., 2005). Recently, Beresnev (2003) reviewed kinematic slip inversion techniques and discussed uncertainties of the inversion among many factors. He asserted that the solution might depend on the array geometry. Custódio et al. (2005) examined the dependence of the kinematic inversion solutions on the data by using 12 equivalent data subsets for the 2004 Parkfield, California, earthquake. Owing to the substantial increase in the number of available strong-motion data, the evaluation of the reliability of the inverted source model so as to investigate how the final solution depends on the number and array geometry of the strong-motion stations has gained importance. Particularly, the reliability of the location of asperities is practically significant to evaluate near-source strong ground motions.

In this article, the source rupture process of the 2004 Chuetsu, mid-Niigata prefecture, earthquake is estimated by using the kinematic linear waveform inversion technique (Hartzell and Heaton, 1983) and the strong-motion data. First, proper velocity structure models to each strong-motion station are constructed by the waveform modeling of the aftershock records. Next, the theoretical Green's functions for the waveform inversion are calculated by using these velocity structure models. The kinematic source rupture process of the 2004 Chuetsu earthquake is then obtained by the waveform inversion of the ground-motion time histories at 22 strong-motion stations. Then, the variations among the many source models obtained by changing the number and combination of stations are discussed to observe the robustness of the inversion result. The difference between the source models deduced from the $S$ wave alone and both the $P$ and $S$ waves is also examined. Finally, some important features of the source process of this event are addressed.

\section{Data Set}

In the following sections, the strong-motion records observed at 22 stations of K-NET, KiK-net, JMA, and the Niigata Prefecture Government are used (Fig. 1). For the KiK-net stations, downhole sensor records are used. The stations belonging to the K-NET, JMA, and the Niigata Prefecture Government have sensors only on the ground surface. The locations and depth of each strong-motion station are listed in Table 1. These stations include most stations within a radius of $50 \mathrm{~km}$ from the epicenter. Two strong-motion stations (K-NET and JMA) located in Ojiya City, which is close to the source fault, are excluded because nonlinear site effects during the mainshock were reported (e.g., Mori and Iwata, 2006; Tokimatsu and Sekiguchi, 2006). The original records are the three components of the acceleration time histories sampled at $200 \mathrm{~Hz}$ for the KiK-net stations and at $100 \mathrm{~Hz}$ for the others. All of the observed acceleration waveform data are numerically integrated into velocity in the time domain, band-pass filtered between 0.05 and $1.0 \mathrm{~Hz}$ using a sixth-order Chebyshev Type I recursive filter with zero-phase shift, and resampled at $10 \mathrm{~Hz}$. 
Table 1

Strong-Motion Stations Used in This Study

\begin{tabular}{cccccl}
\hline Station & $\begin{array}{c}\text { Latitude } \\
\left({ }^{\circ} \mathrm{N}\right)\end{array}$ & $\begin{array}{c}\text { Longitude } \\
\left({ }^{\circ} \mathrm{E}\right)\end{array}$ & $\begin{array}{c}\text { Depth } \\
(\mathrm{m})\end{array}$ & Network & \multicolumn{1}{l}{ Location } \\
\hline NIG014 & 37.638 & 138.959 & 0 & K-NET & Sanjo \\
NIG016 & 37.639 & 138.771 & 0 & K-NET & Teradomari \\
NIG017 & 37.439 & 138.846 & 0 & K-NET & Nagaoka \\
NIG020 & 37.230 & 138.965 & 0 & K-NET & Koide \\
NIG021 & 37.125 & 138.750 & 0 & K-NET & Tokamachi \\
NIG022 & 37.033 & 138.849 & 0 & K-NET & Shiozawa \\
NIG024 & 37.124 & 138.447 & 0 & K-NET & Yasuduka \\
FKS028 & 37.346 & 139.318 & 0 & K-NET & Tadami \\
NIGH01 & 37.424 & 138.891 & 100 & KiK-net & Nagaoka \\
NIGH06 & 37.650 & 138.071 & 100 & KiK-net & Kamo \\
NIGH09 & 37.536 & 138.131 & 100 & KiK-net & Shitada \\
NIGH11 & 37.170 & 138.747 & 200 & KiK-net & Kawanishi \\
NIGH12 & 37.221 & 138.985 & 110 & KiK-net & Yunotani \\
NIGH13 & 37.051 & 138.400 & 100 & KiK-net & Maki \\
NIGH15 & 37.050 & 138.998 & 100 & KiK-net & Muika \\
FKSH21 & 37.339 & 139.318 & 200 & KiK-net & Tadami \\
CB7 & 37.248 & 139.017 & 0 & JMA & Hirokami \\
65030 & 37.473 & 138.995 & 0 & Niigata Prefecture & Tochio \\
65043 & 37.241 & 138.927 & 0 & Niigata Prefecture & Horinouchi \\
65047 & 37.319 & 138.018 & 0 & Niigata Prefecture & Sumon \\
65048 & 37.350 & 138.067 & 0 & Niigata Prefecture & Irihirose \\
65057 & 37.302 & 138.712 & 0 & Niigata Prefecture & Oguni \\
\hline
\end{tabular}

\section{Modeling of Velocity Structure Using} Aftershock Records

\section{Methodology for Velocity Structure Modeling}

A set of well-calibrated Green's functions is indispensable to retrieve a precise kinematic source rupture model from the observed strong ground motions. As previously mentioned, the velocity structure in and around the source region of the 2004 Chuetsu earthquake is rather complicated; therefore, it would be inappropriate to use a single onedimensional velocity structure model for calculating theoretical Green's functions. In the ultimate sense, the use of a three-dimensional velocity structure model seems to be the best option, and the source model obtained using threedimensional Green's functions would be different from that obtained using a single one-dimensional Green's function (e.g., Koketsu et al., 2003; Liu and Archuleta, 2004). However, developing an exact three-dimensional velocity structure model for the entire area in the target region is usually difficult without extensive integrated geophysical explorations. Graves and Wald (2001) tested the influence of the inaccuracy of the Green's function on kinematic source inversions by using synthetic models. They showed that the resolution of the slip distribution obtained with a set of calibrated one-dimensional Green's functions is comparable to that obtained with three-dimensional Green's functions. In particular, if we mainly concentrate on the waves propagating directly upward from the source, then the onedimensional structure could be a good approximation of the wave propagation characteristics of the true three- dimensional structure. Several previous studies (e.g., Ichinose et al., 2003) constructed proper layered structure models to each station based on the waveform modeling of small events and succeeded in obtaining the detailed source rupture process.

In this study, a velocity structure model for each strongmotion station is constructed by the forward modeling of the aftershock records. The $M_{\mathrm{W}} 4.8$ aftershock that occurred at 0435 on 1 November 2004 (JST) is mainly used in this analysis (aftershock \#1 in Table 2). For the stations where the record of this aftershock is not available, the other three aftershocks $\left(M_{\mathrm{W}} 5.4-5.5\right)$ are used (aftershock \#2-\#4 in Table 2). The source time function of these aftershocks is approximated by a point source with a finite duration of the smoothed ramp function. The locations of the aftershocks are assumed by referring to the results of the hypocenter relocation studies by Kato et al. (2005), Okada et al. (2005), and Shibutani et al. (2005). The focal mechanism follows the moment tensor solution determined by F-net. The source duration of the events are tuned up to fit the observed waveforms. The source parameters of these aftershocks are listed in Table 2. The epicenters of these aftershocks are also indicated by open stars in Figure 1.

The reference underground structure model employed here is listed in Table 3. The reference model is assumed based on the $P$-wave velocity structure model obtained from the refraction survey by Ikami et al. (1986) and the $S$-wave velocity structure model obtained from the microtremor array measurements by Yamanaka et al. (2005). For most stations, the $P S$ logging information at the superficial layers released by K-NET and KiK-net is also included above the 
Table 2

Source Parameters of the Aftershocks

\begin{tabular}{|c|c|c|c|c|c|c|c|c|}
\hline \multirow[b]{2}{*}{ Aftershock } & \multicolumn{2}{|c|}{ Origin Time (JST) } & \multirow[b]{2}{*}{ Latitude $\left({ }^{\circ} \mathrm{N}\right)$} & \multirow[b]{2}{*}{ Longitude $\left({ }^{\circ} \mathrm{E}\right)$} & \multirow[b]{2}{*}{ Depth $(\mathrm{km})$} & \multirow[b]{2}{*}{$M_{0}^{*}(\mathrm{Nm})$} & \multirow[b]{2}{*}{ Strike/Dip/Rake $\left({ }^{\circ}\right)$} & \multirow{2}{*}{$\begin{array}{l}\text { Half Duration } \\
(\mathrm{sec})\end{array}$} \\
\hline & (yyyy/mm/dd) & (hr:min:sec) & & & & & & \\
\hline \#1 & 2004/11/01 & $04: 35: 49.0$ & 37.230 & 138.869 & 6.0 & $1.75 \times 10^{16}$ & $216 / 54 / 104$ & 0.5 \\
\hline$\# 2$ & $2004 / 10 / 23$ & $19: 45: 56.8$ & 37.312 & 138.851 & 10.7 & $1.78 \times 10^{17}$ & $217 / 40 / 107$ & 1.2 \\
\hline \#3 & $2004 / 10 / 25$ & $06: 04: 57.3$ & 37.342 & 138.921 & 12.8 & $2.47 \times 10^{17}$ & 215/53/94 & 1.4 \\
\hline \#4 & $2004 / 11 / 08$ & $11: 15: 58.4$ & 37.406 & 138.994 & 3.8 & $2.24 \times 10^{17}$ & 209/38/103 & 1.3 \\
\hline
\end{tabular}

${ }^{*} M_{0}$ is the seismic moment determined by the F-net/NIED.

top layer of the reference structure model. The appropriate thickness of each sedimentary layer is searched for by the nonlinear optimization using the genetic algorithm (GA) (Holland, 1975). The deep structure beneath the bedrock is common for all of the stations. The theoretical Green's function is calculated by using the discrete wavenumber integration method (Bouchon, 1981) with the reflection and transmission matrix (Kennett and Kerry, 1979). This method gives a full Green's function. For the stations where aftershock \#1 is used, the target velocity waveforms are bandpass filtered between 0.05 and $1 \mathrm{~Hz}$. For the other stations where aftershocks \#2, \#3, and \#4 are used, the target velocity waveforms are band-pass filtered between 0.05 and $0.5 \mathrm{~Hz}$ to maintain a point-source approximation, because the magnitude of these aftershocks is greater than aftershock \#1.

The goodness of the waveform fitting is evaluated by using the following misfit function first introduced by Sen and Stoffa (1991):

$$
f(\tau)=1.0-2 \frac{\int u(t)_{\mathrm{obs}} u(t+\tau)_{\mathrm{syn}} d t}{\int\left[u(t)_{\mathrm{obs}}^{2}+u(t+\tau)_{\mathrm{syn}}^{2}\right] d t} .
$$

Here, $u(t)_{\mathrm{obs}}$ and $u(t)_{\mathrm{syn}}$ are the observed and synthesized waveforms, respectively, and $\tau$ is the time shift to compensate for the error in the absolute travel time between them. The unknown parameters are estimated so as to minimize $f(\tau)$ using the GA developed by Carroll (1996). In our problem, the material parameters (elastic wave velocity, density, and $Q$ values) for each sedimentary layer are fixed during the optimization, and the unknown parameters are the thicknesses of several sedimentary layers only. The initial popula- tion that consists of 40 models is randomly generated. Then, the evolution process, including the tournament selection, uniform crossover, jump and creep mutation, and elitism (best individual replicated into next generation), is applied to the population to produce the next generation with the same population size. In this simulation, the crossover probability, jump mutation probability, and creep mutation probability is $0.5,0.025$, and 0.125 , respectively. These parameters are determined according to Carroll (1996). The reproduction and selection procedure is terminated at the fiftieth generation. In order to obtain a stable solution, five runs are tested, by changing the initial models, for each station. The best model among the five is selected as the final solution.

\section{Estimated Velocity Structure Model}

According to the methodology described in the previous subsection, the one-dimensional velocity structure models for 22 stations are constructed. Figure $2 \mathrm{a}$ shows the minimum misfit value at each generation for each GA run in the case of waveform modeling of aftershock \#1 for NIGH11. The misfit values decrease rapidly in the first 10-20 generations. This shows convergence near the minimum solution. The velocity structure model obtained here is shown in Figure $2 \mathrm{~b}$. The final model with the minimum misfit value among the best-fit models obtained by each run and the other four models are indicated by solid and broken lines, respectively. These five models closely resemble each other, so that the appropriate structure model is stably estimated by the procedure. Figure $2 \mathrm{c}, \mathrm{d}$ shows comparison among the bestfit model using aftershocks \#1, \#2, and \#4. These three

Table 3

Reference Underground Structure Model to Estimate Velocity Structure Model for Each Station

\begin{tabular}{ccccccc}
\hline Layer & Depth $(\mathrm{m})$ & $V_{P}(\mathrm{~m} / \mathrm{sec})$ & $V_{S}(\mathrm{~m} / \mathrm{sec})$ & $\rho\left(\mathrm{kg} / \mathrm{m}^{3}\right)$ & \multicolumn{1}{c}{$Q_{P}$} & \multicolumn{1}{c}{$Q_{S}$} \\
\hline$\# 1$ & 0 & 1800 & 600 & 1800 & 100 & 50 \\
$\# 2$ & Variable & 2200 & 1000 & 2100 & 200 & 100 \\
$\# 3$ & Variable & 2600 & 1300 & 2200 & 300 & 150 \\
$\# 4$ & Variable & 3100 & 1790 & 2300 & 400 & 200 \\
$\# 5$ & Variable & 4100 & 2370 & 2400 & 500 & 250 \\
$\# 6$ & Variable & 4700 & 2710 & 2550 & 600 & 300 \\
Upper crust & Variable & 6000 & 3460 & 2670 & 700 & 350 \\
Lower crust & 17,000 & 6700 & 3870 & 2900 & 800 & 400 \\
Upper mantle & 34,000 & 7900 & 4400 & 3200 & 1000 & 500 \\
\hline
\end{tabular}



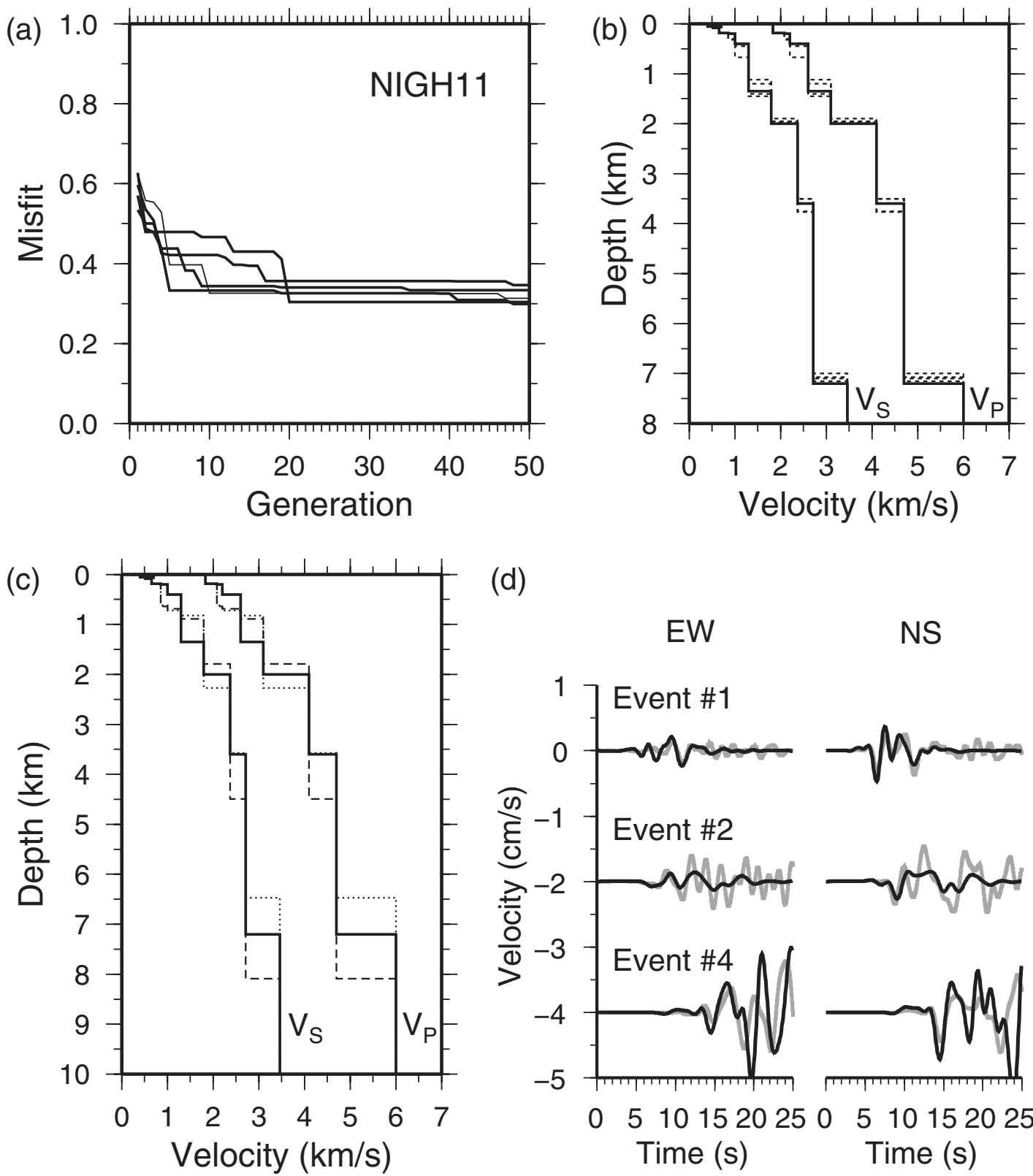

(d)
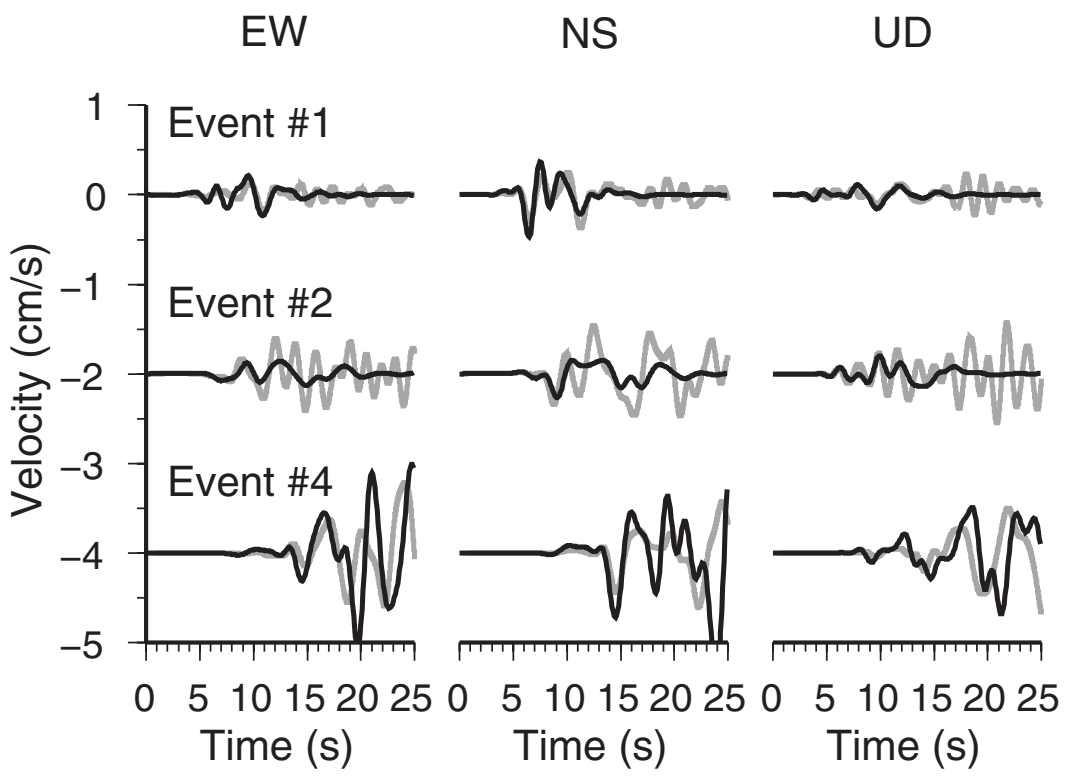

Figure 2. Results of velocity structure modeling for NIGH11. (a) The minimum misfit value as a function of generation for five GA runs using aftershock \#1 for NIGH11. (b) The best-fit subsurface velocity structure models obtained using aftershock \#1 for NIGH11. The solid line indicates the best model among five runs, and broken lines indicate models obtained from the other four runs. (c) Comparison of the best-fit models obtained using aftershock \#1 (solid line), \#2 (broken line), and \#4 (dotted line) for NIGH11. (d) Comparison between observed (gray line) and synthesized (solid black line) velocity waveforms for aftershocks \#1, \#2, and \#4.

models are fairly similar to each other. It supports that the effective one-dimensional velocity structure model proposed here works well though small differences among three models still remain. These differences may be due to threedimensional effects along the propagation path.

Figure 3 shows the estimated velocity structure models for all of the stations. The synthetic velocity waveforms calculated from the obtained velocity structure model are plotted with the observed ones in Figure 4. The synthetic waveforms reproduce the observed ground motions fairly well in the frequency range considered. The stations located inside the basins and valleys have thicker sediment layers than other stations. In particular, the bedrock depths at several stations are deeper than $5 \mathrm{~km}$. The stations located at the footwall side have thin sediments. The estimated bedrock depth ranges from $0.5 \mathrm{~km}$ to $7.7 \mathrm{~km}$. These overall features are consistent with the three-dimensional inhomogeneous velocity structure models obtained by the tomography studies that are mentioned in the Introduction section of this article. These obtained velocity structure models are used to calculate the Green's functions for the waveform inversion study in the following sections. 

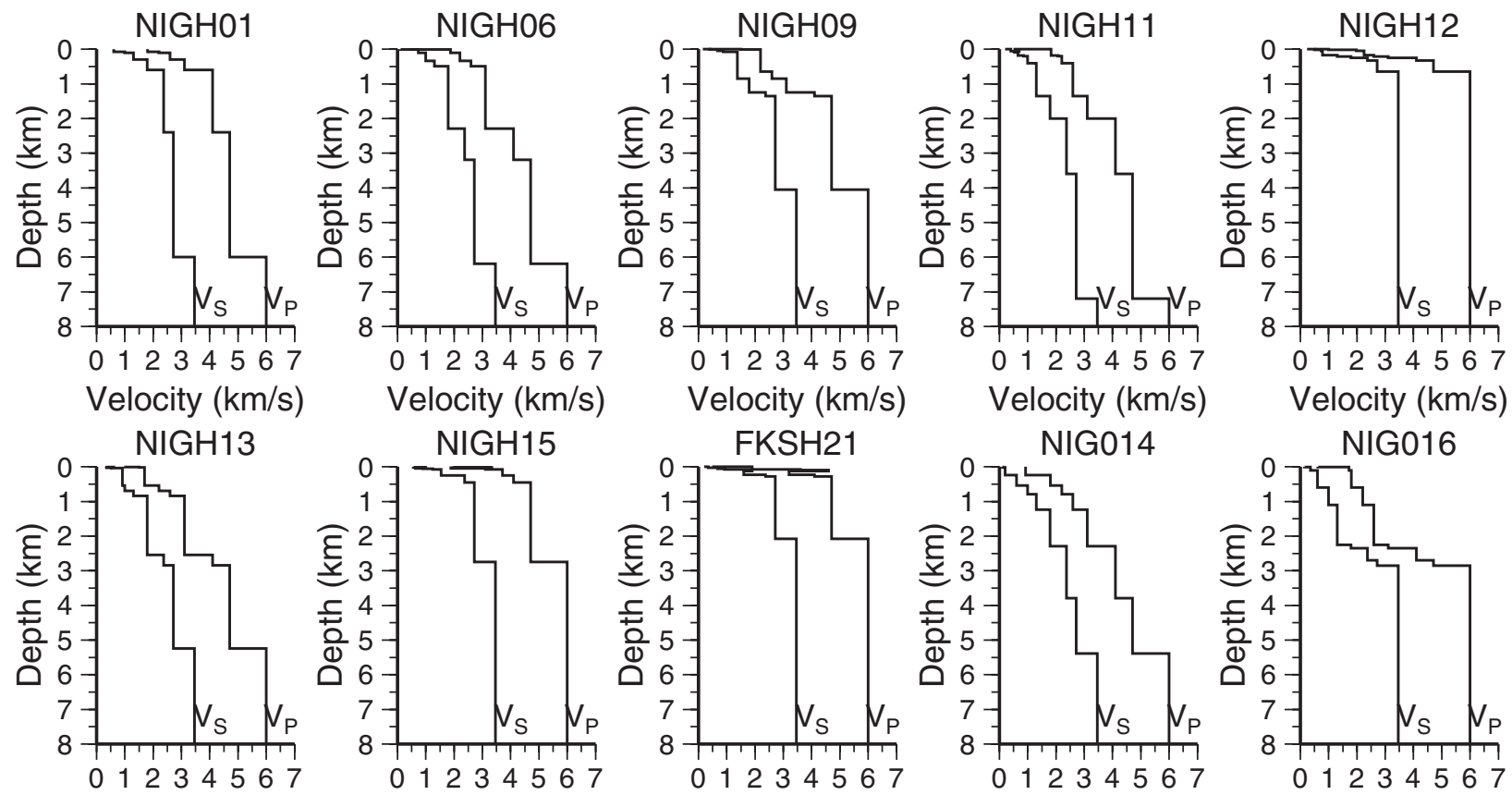

Velocity $(\mathrm{km} / \mathrm{s})$

Velocity $(\mathrm{km} / \mathrm{s})$
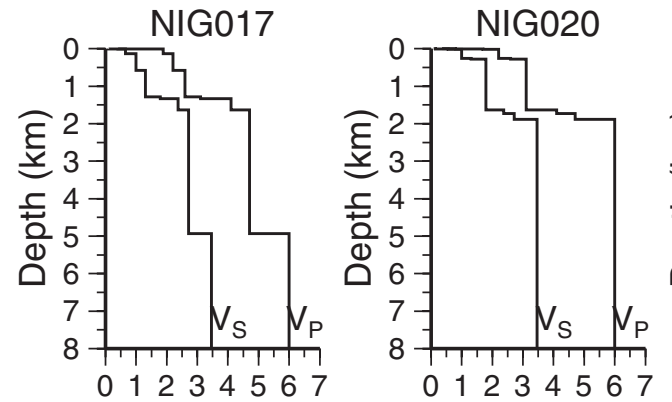

Velocity $(\mathrm{km} / \mathrm{s})$
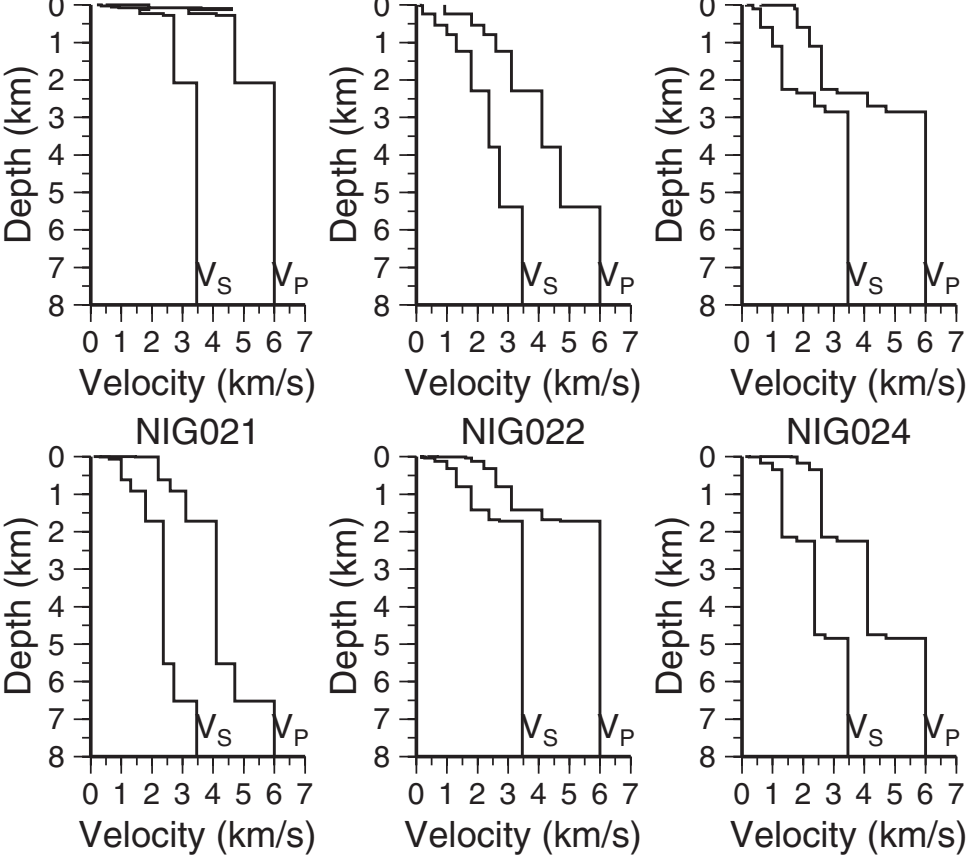

Velocity $(\mathrm{km} / \mathrm{s})$
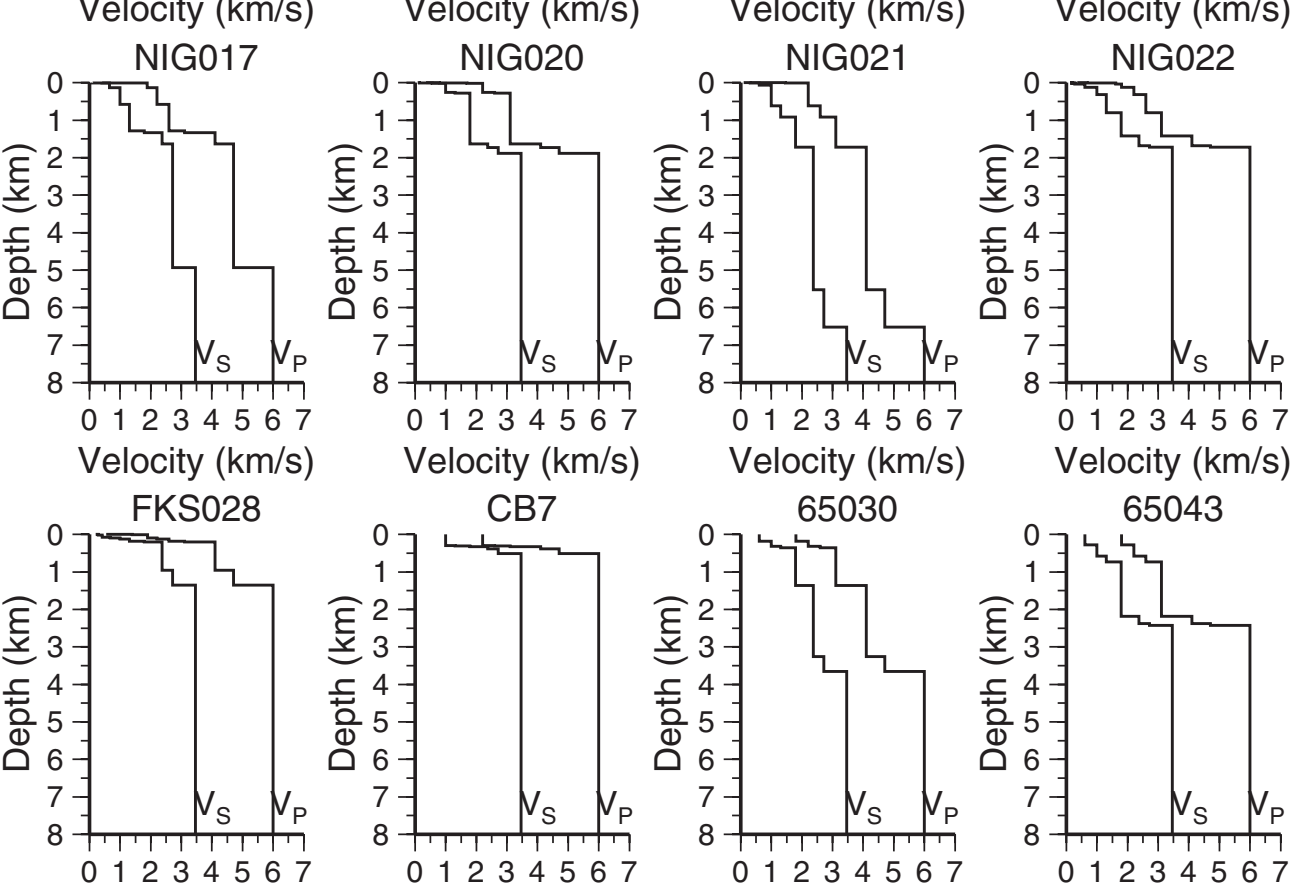

Velocity $(\mathrm{km} / \mathrm{s})$

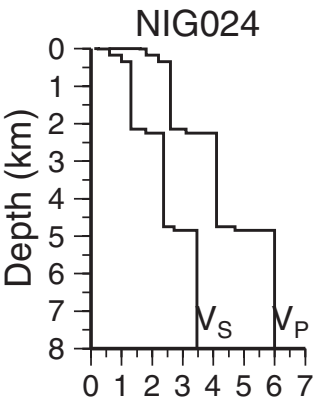

Velocity $(\mathrm{km} / \mathrm{s})$

Velocity $(\mathrm{km} / \mathrm{s})$

Velocity $(\mathrm{km} / \mathrm{s})$

Velocity $(\mathrm{km} / \mathrm{s})$

Velocity $(\mathrm{km} / \mathrm{s})$
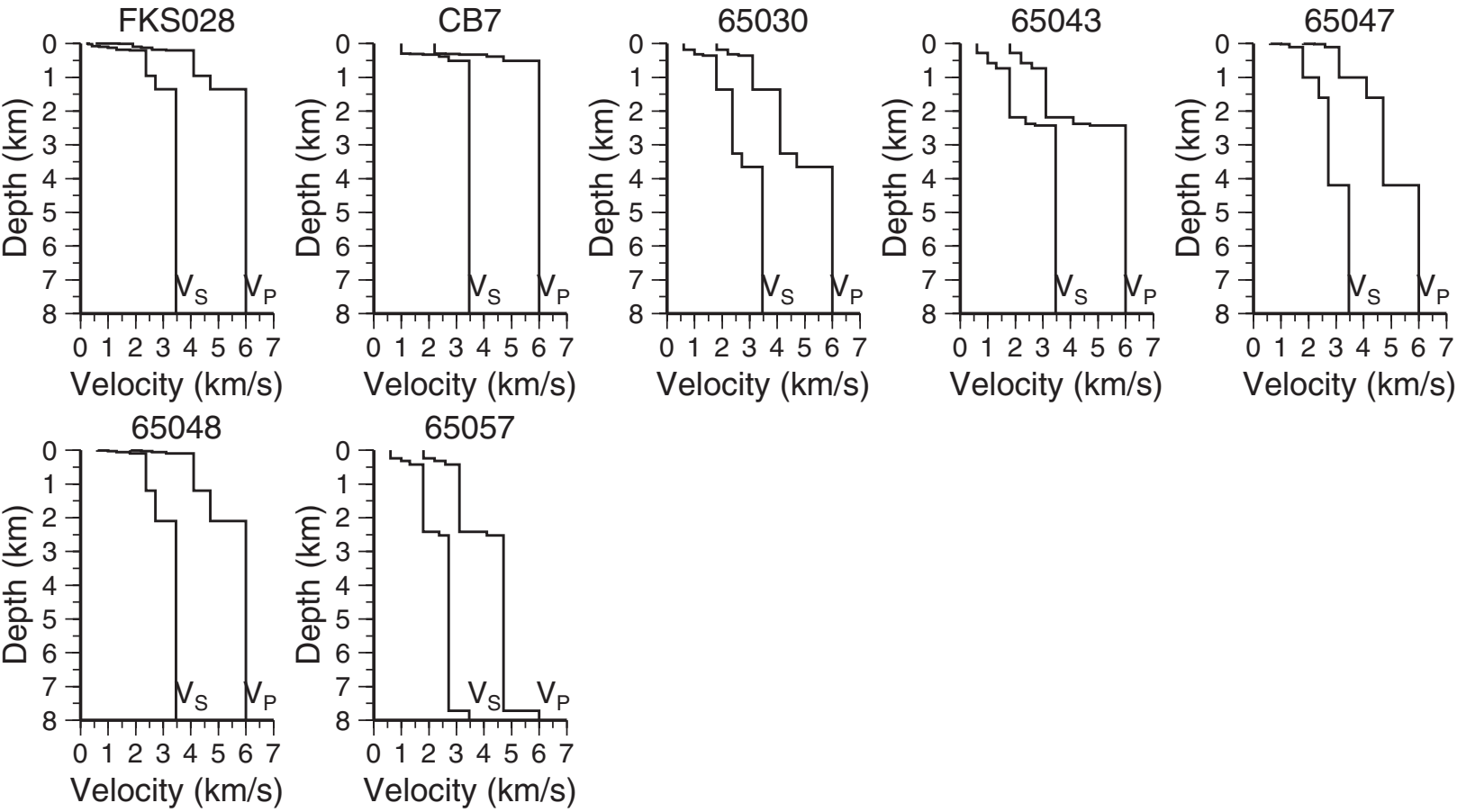

Figure 3. $\quad P$ - and $S$-wave velocity structure model above the bedrock for each station estimated by modeling aftershock waveforms. 
EW

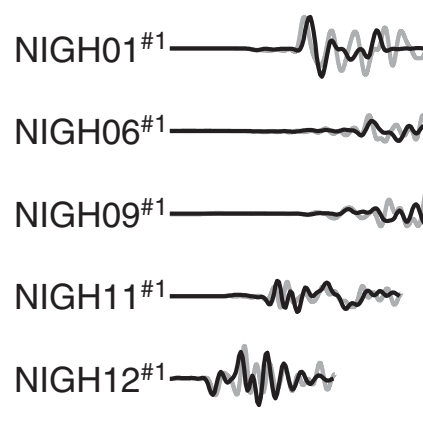

NIGH13"1_numphr

NIGH15 \#1_unhara

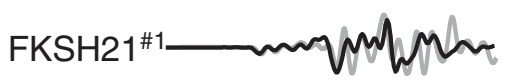

NIG014"1__anespers

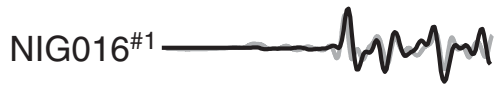

NIG017"1__hyph

NIG020\#1 Mpana

NIG021"1__manned

NIG022\#1 — Wh

NIG024"\#1_monown

FKS028\#1_moflym

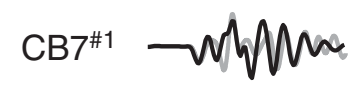

65030"4 ک

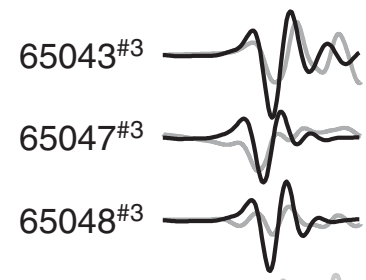

$65057^{\# 2}$

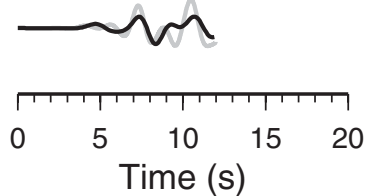

NS
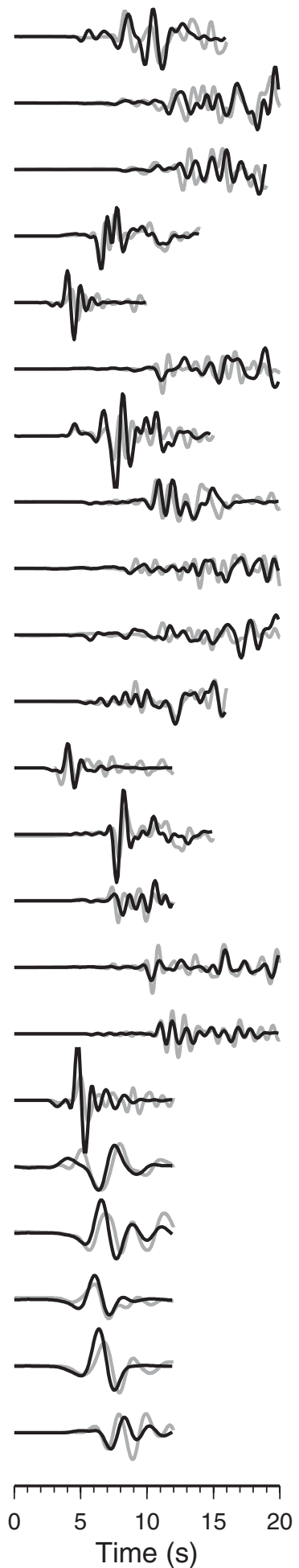

UD
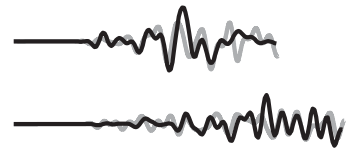

why
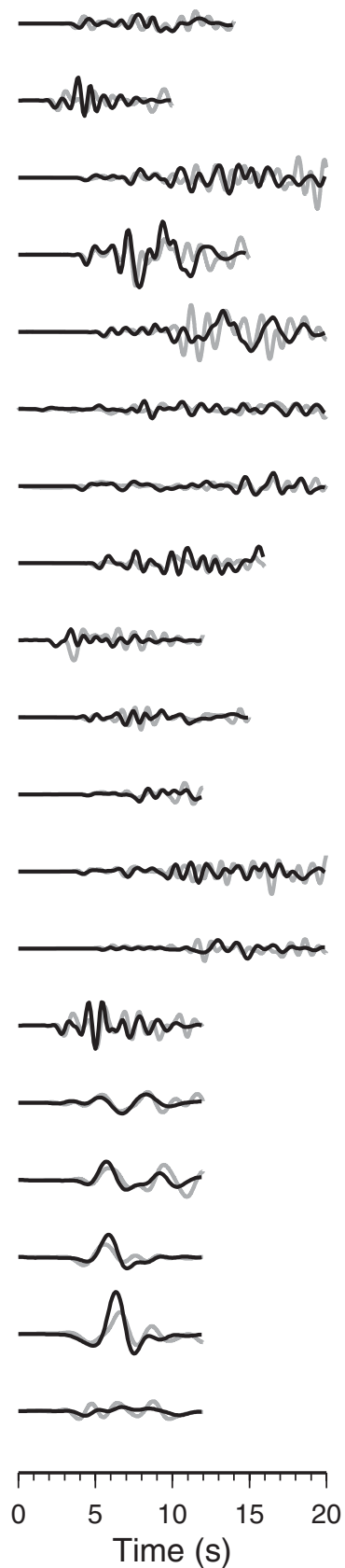

Figure 4. Comparison between observed velocity waveforms (gray line) and synthesized velocity waveforms for the aftershock modeling (solid black line). The number associated with each station code denotes the aftershock in Table 2 . The amplitude is normalized by the maximum amplitude of observation for each station. 


\section{Waveform Inversion to Estimate Kinematic Source Model}

\section{Waveform Inversion Method}

The spatial and temporal rupture history is estimated by the multiple-time-window linear waveform inversion method (Harztell and Heaton, 1983). A planar fault plane is assumed by referring to the aftershock distribution, and its length and width are set to 28 and $18 \mathrm{~km}$, respectively. The strike $\left(212^{\circ}\right)$ and dip angle $\left(47^{\circ}\right)$ of the fault plane follows the moment tensor solution determined by F-net. The hypocenter or rupture initiation point is assumed to be $37.307^{\circ} \mathrm{N}, 138.839^{\circ} \mathrm{E}$ at a depth of $10.6 \mathrm{~km}$. This hypocenter location is obtained by averaging the results from the precise hypocenter relocating studies by Kato et al., (2005), Okada et al. (2005), and Shibutani et al. (2005). The original hypocenters of these studies are close to each other. The moment release on the fault is discretized in space and time. The fault plane is divided into 126 subfaults. Each subfault has a length of $2 \mathrm{~km}$ and width of $2 \mathrm{~km}$. A point source is located at the center of each subfault. The depth of the point source for the uppermost subfaults is $1.8 \mathrm{~km}$. The temporal moment release from each subfault is expressed by a series of six smoothed ramp functions with a rise time of $1.0 \mathrm{sec}$ separated by $0.5 \mathrm{sec}$ $(\Delta t w)$. Circular rupture propagation at a constant velocity $V_{R}$ from the hypocenter is assumed. The observational equation is expressed in the vector form as

\section{$\mathbf{A m} \cong \mathbf{d}$,}

with

$$
\begin{gathered}
A_{p q}=G_{n i}\left[x_{s}, t_{l}-R_{k} / V_{R}-(j-1) \Delta t w ; \xi_{k}, 0\right], \\
m_{q}=\Delta u_{i j k}, \quad d_{p}=u_{n}\left(x_{s}, t_{l}\right), \\
p=(s-1) L N+(n-1) L+l, \\
(s=1, \ldots, S, n=1, \ldots, N, l=1, \ldots L), \\
q=(i-1) J K+(j-1) K+k, \\
(i=1, \ldots I, j=1, \ldots, J, k=1, \ldots, K),
\end{gathered}
$$

where $u_{n}$ is the $n$th component of the observed velocity waveform at the $l$ th sampled time at the sth station, $\Delta u_{i j k}$ is the $i$ th component of slip at the $j$ th time window at the $k$ th subfault, $G_{n i}$ is the $n$th component of the Green's function convolved with the element source time function corresponding to the $i$ th component of the slip at the $k$ th subfault, and $R_{k}$ is the distance from the rupture initiation point to the center of the $k$ th subfault. $I, J, K, L, N$, and $S$ are the total number of slip components (here, $I=2$ as slip has dip and strike-slip components), time windows, subfaults, data samples of each component, data components (here, $N=3$ as observed data has three components), and stations, respectively. The rupture propagation velocity $V_{R}$, which triggers the rupture of the first time window at each subfault, is de- termined so as to minimize the residual of the data fitting. Here, eight values-1.73, 1.90, 2.08, 2.25, 2.42, 2.60, 2.77, and $2.94 \mathrm{~km} / \mathrm{sec}$ - are tested. They correspond to 50,55 , $60,65,70,75,80$, and $85 \%$ of the shear-wave velocity of the upper crust model, respectively. The amplitude of the waveforms is normalized by the maximum amplitude at each station.

The spatiotemporal smoothing constraint is introduced to stabilize the inversion result according to Sekiguchi et al. (2000). This smoothing constraint assumes the model parameters close in space and time to be similar. The smoothing constraint equations for all of the model parameters are combined in the matrix form as

$$
\mathbf{S m} \cong 0
$$

Equations (2) and (4) can be combined as

$$
\left(\begin{array}{c}
\mathbf{A} \\
\lambda \mathbf{S}
\end{array}\right) \mathbf{m} \cong\left(\begin{array}{l}
\mathbf{d} \\
0
\end{array}\right) .
$$

A hyperparameter describing the relative strength of smoothing, $\lambda$, is determined by Akaike's Bayesian Information Criterion approach (Akaike, 1980). Because the focal mechanism of this earthquake is reverse faulting, the rake angle direction is limited within $90^{\circ} \pm 45^{\circ}$. The detail of the technique applied here is described in Sekiguchi et al. (2000). Because we are mainly interested in the $S$-wave portion of the ground motions, the $12 \mathrm{sec}$ of time histories beginning from $1 \mathrm{sec}$ prior to the direct $S$-wave onset are used. Equation (5) is solved to obtain the unknown model parameter $\boldsymbol{m}$ using the non-negative least-squares algorithm (Lawson and Hanson, 1974).

\section{Result}

The obtained final slip distribution on the fault surface is shown in Figure 5. Figure 6 shows the comparison between the observed and synthesized velocity waveforms in $0.05-1 \mathrm{~Hz}$. The observed waveforms exhibit a complicated behavior even in the low-frequency range. The synthesized waveforms fit the observed waveforms fairly well, although some discrepancies still remain. The rupture front propagation velocity of the first time window is selected as $1.90 \mathrm{~km} / \mathrm{sec}$ to give the best-fit model. This rupture velocity corresponds to approximately $55 \%$ of the shear-wave velocity in the upper crust, and it is slower than the average rupture velocity of the shallow crustal earthquakes compiled by Geller (1976). A large slip area or asperity is observed in the vicinity of the hypocenter. Its maximum slip amount is $3.1 \mathrm{~m}$. The average slip amount over the fault is approximately $0.7 \mathrm{~m}$. The estimated total seismic moment is $1.07 \times 10^{19} \mathrm{Nm}\left(M_{\mathrm{W}}\right.$ 6.6). Figure 7 shows the temporal progression of the slip. Figure 8 shows the moment-rate functions of each subfault. The maximum moment rate is observed at the hypocenter. The rupture originated from the 


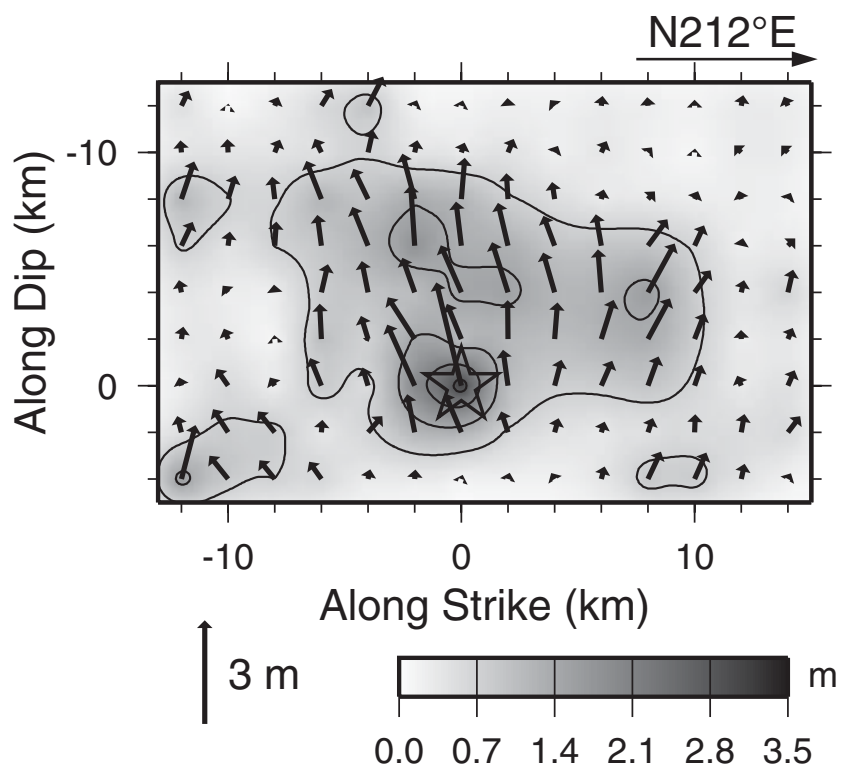

Figure 5. Final slip distribution obtained from the waveform inversion. The open star indicates the hypocenter. The arrows show slip vectors of the hanging wall relative to the footwall. The slip distribution is interpolated by the minimum curvature gridding algorithm (Smith and Wessel, 1990). The contour interval is $0.7 \mathrm{~m}$.

deep part of the source fault and propagated toward the updip direction with a slightly lower rupture velocity. The asperity also extended along the southwest direction. The large pulse observed in the ground motions southwest of the fault (NIG021, NIGH11) are mainly contributed by the slip in the southwest portion of that asperity, whereas the ground motions at the other stations are controlled by the large slip in and around the hypocenter. Most of the slip is observed in an area of $20 \mathrm{~km} \times 12 \mathrm{~km}$. The slip near the ground surface is not significant. This is consistent with the field observations, which reported that no obvious surface faulting was observed along the surface projection of the top of the fault plane. The entire rupture lasted for approximately $10 \mathrm{sec}$.

\section{Robustness of Inversion Solutions}

\section{Overview}

In the previous section, the source model of the 2004 Chuetsu earthquake was constructed using the strong-motion data recorded at 22 stations within a radius of $50 \mathrm{~km}$ from the epicenter. Because this earthquake occurred in the inland area of Japan, the strong-motion stations are located above and around the source region. The coverage of the stations appears to be good. The influence of the spatial configuration of the observation stations on the resolvability of the inverted fault slip model has been examined in previous studies (e.g., Iida et al., 1990; Saraó et al., 1998). Iida et al. (1988) proposed the optimum array configuration to perform the source inversion for strike-slip and inclined dip-slip fault earthquakes based on the prediction analysis. The resultant source model might depend on the selection of stations in some cases. Custódio et al. (2005) practically investigated how the resulting source models depend on the data. They prepared 12 equivalent data subsets for the 2004 Parkfield, California, earthquake, and compared the inversion results. Their primary conclusion was that common features could be identified despite some variability between the models, and they insisted that only these persistent features should be considered as accurate when concluding the earthquake fault dynamics. However, the problem of determining how many strong-motion stations are required in order to obtain a robust solution has not been suitably addressed in practical cases. In the following subsection, we will demonstrate how the solutions depend on the number of stations used in the inversion. Here, we treat the solution obtained in the previous section as the reference solution and compare the results from different data sets and discuss their robustness and varieties. In the subsequent subsection, the difference between the solution from only the $S$ wave and that from the $P$ and $S$ waves will be discussed to check whether the $S$-wave part has sufficient resolution to retrieve a precise rupture model. From these tests, the reliability of the location of the large slip area or asperities within the fault plane can be confirmed.

Variation of Inversion Results among Different Station Combinations

In order to examine the influence of the number of stations $\left(N_{s}\right)$ included in the waveform inversion on the obtained source model, inversion analyses by changing the number of stations are performed following the jackknife resampling technique (e.g., Efron, 1982). Four cases, in which $N_{s}$ are $4,8,12$, and 16 , respectively, are tested. Twenty-two stations are divided into four groups according to the azimuth from the epicenter. Each group consists of five or six stations. In order to build a data set, $N_{s} / 4$ stations are chosen from each group. For each case, 200 combinations of stations are randomly generated using the pseudo random number generator MT19937 (Matsumoto and Nishimura, 1998). According to the inversion result using all of the data, which was shown in the previous section, the rupture propagation velocity of the first time window is fixed at $1.90 \mathrm{~km} / \mathrm{sec}$. It is because we would like to only see the effect of the station configurations in the test.

Figure 9 shows the maps of the average slip model obtained by averaging the 200 models (a), their standard deviation (b), and coefficient of variance (c) for each $N_{s}$. The coefficient of variance is calculated by dividing the standard deviation by the average value (Custódio et al., 2005). The average slip models for each $N_{s}$ are quite similar to each other and to the reference source model. The standard deviation of slip models decreases with an increase in the number of stations. The coefficient of variance is large at the edge of the fault area and small in the large slip area. At the edge of the fault area, the slip is not constrained well by the data. When $N_{s}=12$ or 16 , the standard deviation is very small when compared to the final slip amounts, and the coefficient 
Obs.

Syn.

$\begin{array}{lllll}\text { EW } & \text { NS } & \text { UD } & \text { NS }\end{array}$

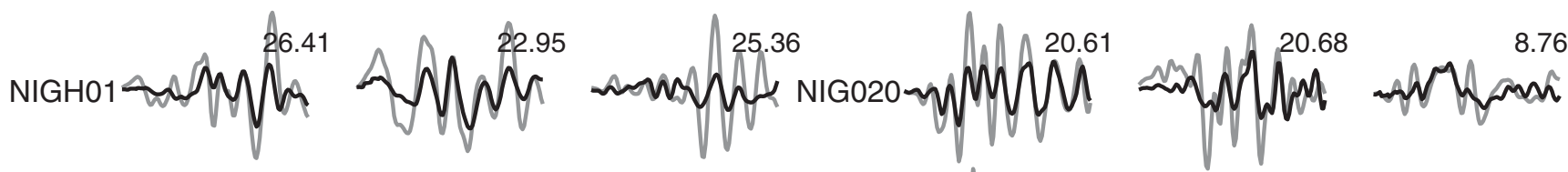

NIGH06- Dap M.

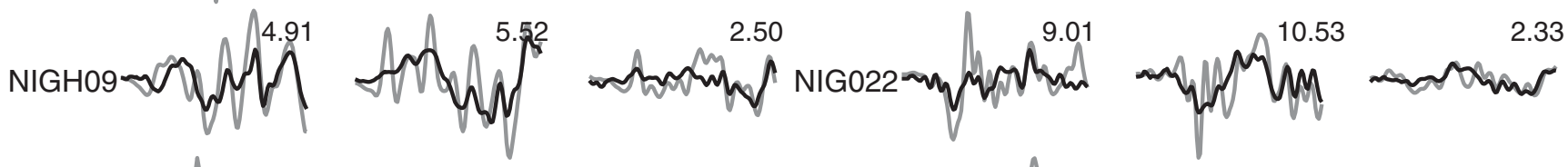

NIGH11

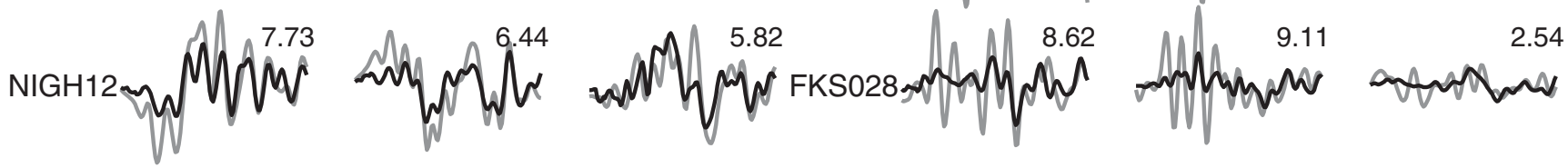

NIGH13 rov

NIGH15 on

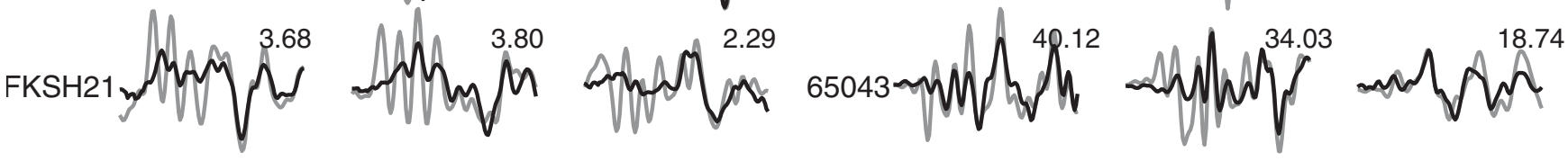

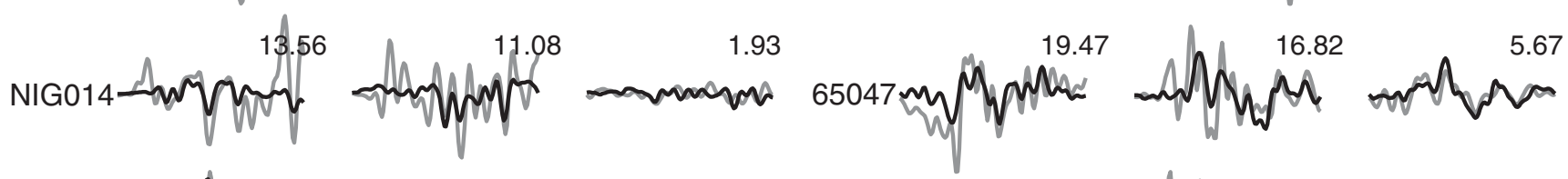

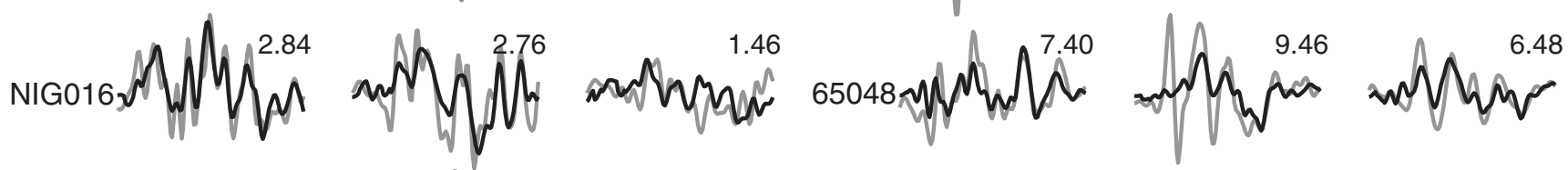

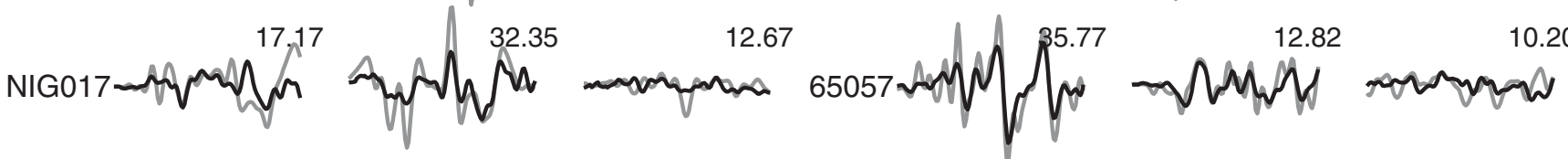

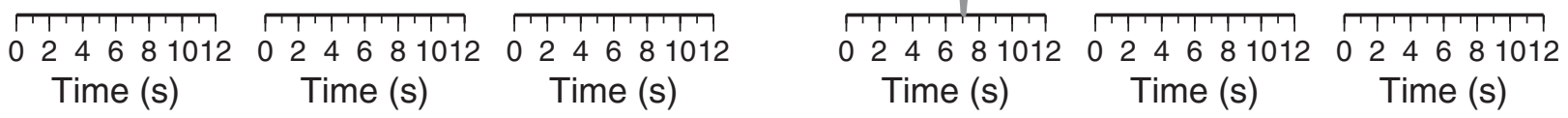

Figure 6. Comparison between observed velocity waveforms (gray line) and synthesized velocity waveforms (solid black line) obtained from the waveform inversion. Each waveform is band-pass filtered between 0.05 and $1 \mathrm{~Hz}$. The maximum amplitude of each component of the observed waveforms is shown above each trace in $\mathrm{cm} / \mathrm{sec}$. 

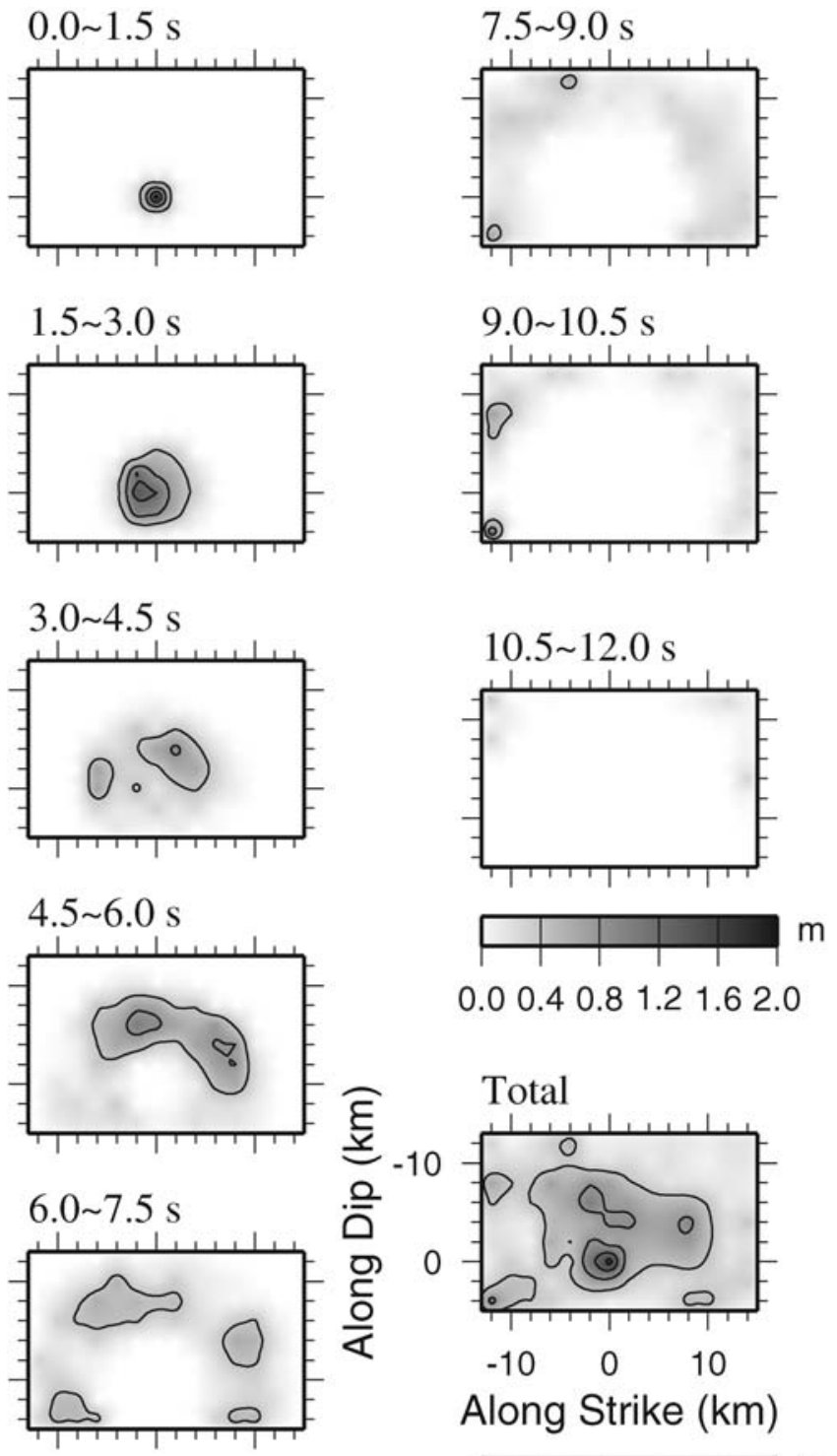

0.00 .40 .81 .21 .62 .0

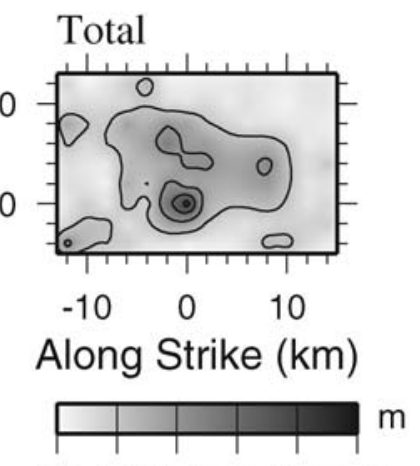

0.00 .71 .42 .12 .83 .5

Figure 7. Snapshots of the temporal rupture progression at timesteps of $1.5 \mathrm{sec}$. The contour interval of the slip is $0.4 \mathrm{~m}$. The open star indicates the rupture starting point.

of variance is less than 0.3 at most areas of the fault. Even for the case of $N_{s}=8$, the coefficient of variance in the asperity area is less than 0.3 . These facts imply that the pattern of slip distribution is stably estimated from these data sets, and the location of asperities does not change. For $N_{s}=4$, because the standard deviation and coefficient of variance are large in the entire fault area, the amount of data is not sufficient to obtain a stable solution. Figure 10 is the histogram of the slip amount at four subfaults obtained for each model. The subfault $(7,7)$ corresponds to the rupture initiation point, where the maximum slip was observed for the reference slip model. The subfault $(14,1)$ is the subfault at the fault edge, where the variance is relatively large. For $N_{s}=4$, some of the mod- els have extreme slip amounts at $(14,1)$. These models would not be realistic. With an increase in the number of stations used in the inversion, the slip amount converged at the reference value and the standard deviation decreased. This feature is consistent with the result of Iida et al. (1990), in which the uncertainty of the slip amount decreased with an increase in the number of stations. Figures 9 and 10 suggest that it is necessary to use more than 12 uniformly distributed stations to retrieve a stable source model for the 2004 Chuetsu earthquake.

\section{Effects of Target Wave Type and Velocity Structure Model}

In our analysis, the time window beginning from one second prior to the $S$-wave onset of the ground motions is used as the input data set for the waveform inversion. The onset of the direct $S$-wave arrival is manually picked up. In the case of near-source strong ground motions, the later part of the direct $P$ wave is contaminated by the large amplitude of the $S$ wave because the $S$ - $P$ time in the near-source region is shorter than the source duration time of the target event. Kinematic waveform inversion study with strong-motion data has mainly utilized the $S$-wave part of the ground motions because it is interested in the generation process of strong ground motion in $S$ wave and its later phases. Some previous studies simultaneously analyzed both $P$ and $S$ waves of ground motions (i.e., a time window beginning prior to the $P$-wave onset is used). However, to precisely achieve the simultaneous inversion of $P$ and $S$ waves, the careful treatment of the Green's function is quite important because error in $S$ - $P$ time in the Green's function will affect the resulting slip model. In this article, appropriate velocity structure models have already been constructed for each strong-motion station. In order to check the reliability of the source model deduced from the $S$ wave, another inversion is demonstrated by using both the $P$ and $S$ waves. Hereafter, the term $S$-wave inversion indicates the waveform inversion using the time history of $12 \mathrm{sec}$ from $1 \mathrm{sec}$ before the direct $S$-wave arrival; the term $P$ - and $S$-wave inversion indicates the waveform inversion using the time history of $20 \mathrm{sec}$ from $1 \mathrm{sec}$ prior to the direct $P$-wave arrival. The waveform inversion methodology and the Green's functions are the same in both analyses. Because the Green's function is a full Green's function, both $S$-wave inversion and $P$ - and $S$-wave inversion include all of the phases in the targeted time window. The best rupture propagation velocity of the first time window is searched, changing by $5 \%$ of the $S$-wave velocity $(3.46 \mathrm{~km} / \mathrm{sec})$ in a similar fashion to the $S$-wave inversion.

Figure 11 shows the comparison between the source model obtained from the $S$-wave inversion (Fig. 11a) and that obtained from the $P$ - and $S$-wave inversion (Fig. 11b). The comparison between observed and synthetic waveforms is shown in Figure 12. The rupture propagation velocity of $1.90 \mathrm{~km} / \mathrm{sec}$ was selected for $P$ - and $S$-wave inversion. It was the same as the result of the $S$-wave inversion. The spa- 


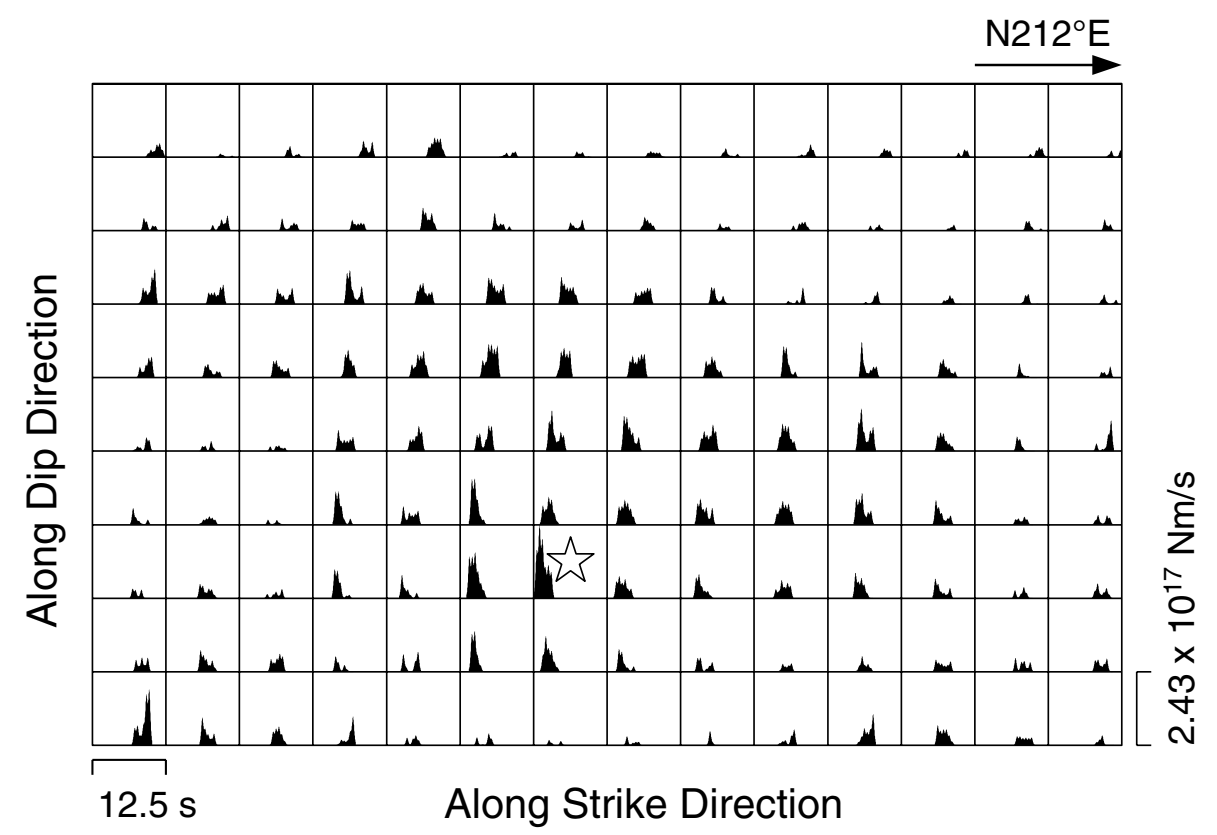

Figure 8. Moment-rate functions of each subfault. The open star indicates the hypocenter.

tial extent of large slip area in the source model of the $P$ - and $S$-wave inversion is similar to that of the $S$-wave inversion. It should be noted that this kind of comparison is impossible when the velocity structure model and hypocenter location cannot explain the observed $S$ - $P$ time. If the number of stations is sufficient and the errors in picking up the $S$-wave phase are not systematic, then these errors could be compensated for in the $S$-wave inversion. Therefore, it could be concluded that both analyses could accurately locate the asperities when the appropriateness of the Green's function is verified in the target area.

In Figure 11c, the final slip distribution obtained using a single velocity structure model is also shown as a comparison. In this model, the velocity structure model for NIGH12 is used for all of the stations. Because NIGH12 has thin lowvelocity sedimentary layers, this velocity model is close to a rock model, which is commonly used in the kinematic source inversion practices. The models obtained using calibrated velocity structure models show a clear image of highslip area compared to the model obtained using a single velocity structure model. It reveals the importance of velocity structure calibration demonstrated in this article.

\section{Discussions}

Because of the strong heterogeneity and uncertainty of the velocity structure in this region, it is still difficult to infer the relationship between the fault rupture process of this earthquake and the geophysical and geological structures. Many ongoing studies are investigating the tectonic environment of this earthquake. According to the obtained slip distribution as shown in Figure 5, almost no slip was observed at the depth shallower than $3 \mathrm{~km}$. In that depth, few after- shocks occurred (e.g., Shibutani et al., 2005; Okada et al. 2006). That feature supports the result that the rupture of the mainshock did not extend to ground surface because aftershock distribution usually corresponds to the rupture area in terms of spatial coverage. The $P$ - and $S$-wave velocity structure models obtained from the double-difference tomography by Okada et al. (2006) indicated thick low-velocity layers overlying the aftershock area of the mainshock. This lowvelocity layer extends from the hanging-wall to the footwall side and spatially corresponds to the area with no slip and few aftershocks. That is, the asperities of this earthquake are located in the crust with high seismic wave velocity. Nishigami (2006) estimated the three-dimensional distribution of the relative scattering coefficients in the source region by the inversion of the coda energy fluctuation. The asperity obtained in our study seems to correspond to a relatively weak scattering region, and the asperity area is bounded by the strong heterogeneous zone with large scattering coefficients. The rupture area of this earthquake might be blocked by the geological segment structure.

As previously mentioned, the rupture near the ground surface is small; therefore, this earthquake could be categorized as a buried rupture earthquake. Kagawa et al. (2004) pointed out that buried rupture earthquakes have a larger stress drop on the asperity and generate stronger short-period (around $1 \mathrm{sec}$ ) ground motions as compared to surface breaking earthquakes. The static stress change of this earthquake is calculated from the source model obtained in this study according to the methodology developed by Ripperger and Mai (2004). Figure 13 shows the distribution of the static stress drop on the fault. The static stress drops on the asperities are locally higher than $10 \mathrm{MPa}$. Kamae et al. (2005) estimated the stress drop on the asperities by the forward modeling 
(a) Average

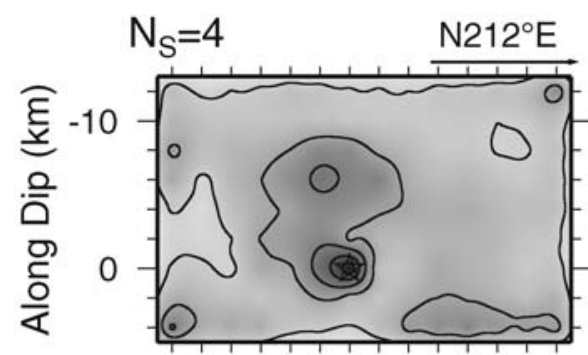

$\mathrm{N}_{\mathrm{S}}=8$

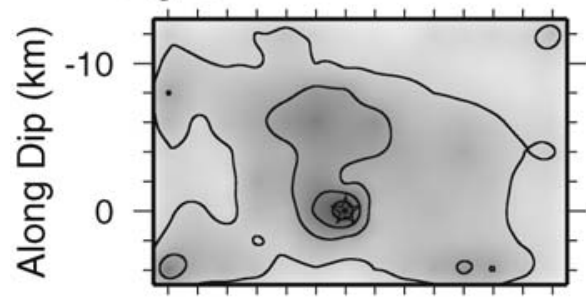

$\mathrm{N}_{\mathrm{S}}=12$

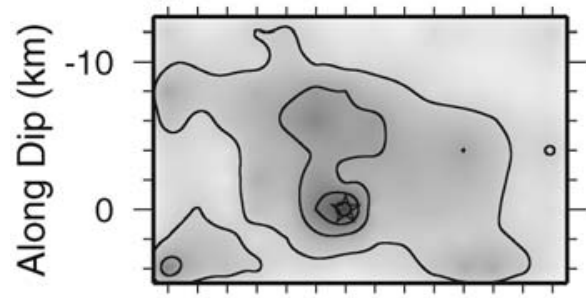

$\mathrm{N}_{\mathrm{S}}=16$

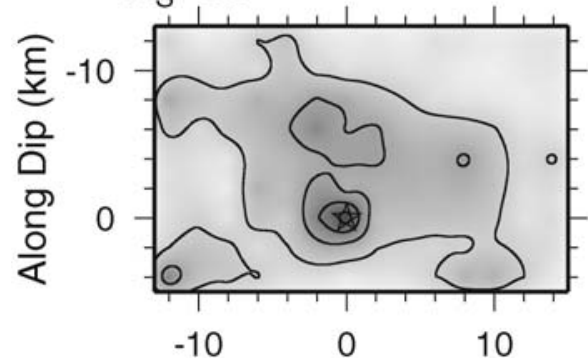

Along Strike $(\mathrm{km})$ (b) Standard Deviation
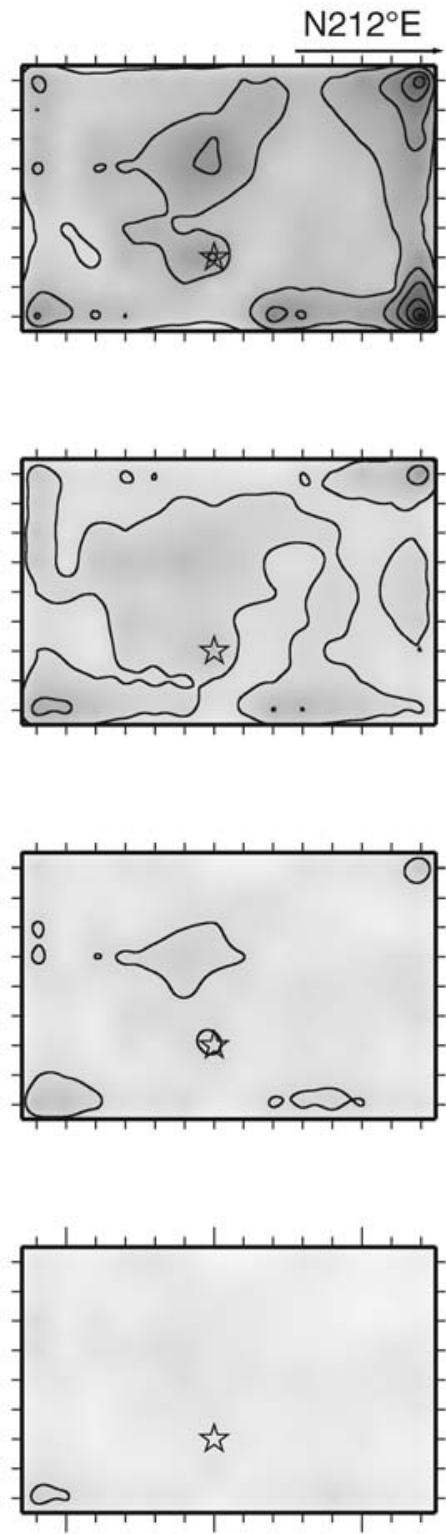

$\begin{array}{lll}-10 & 0 & 10\end{array}$

Along Strike $(\mathrm{km})$
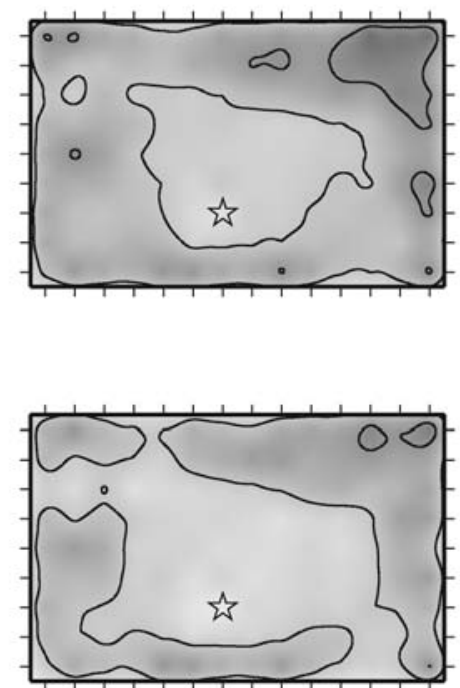

(c) Coefficient of Variance
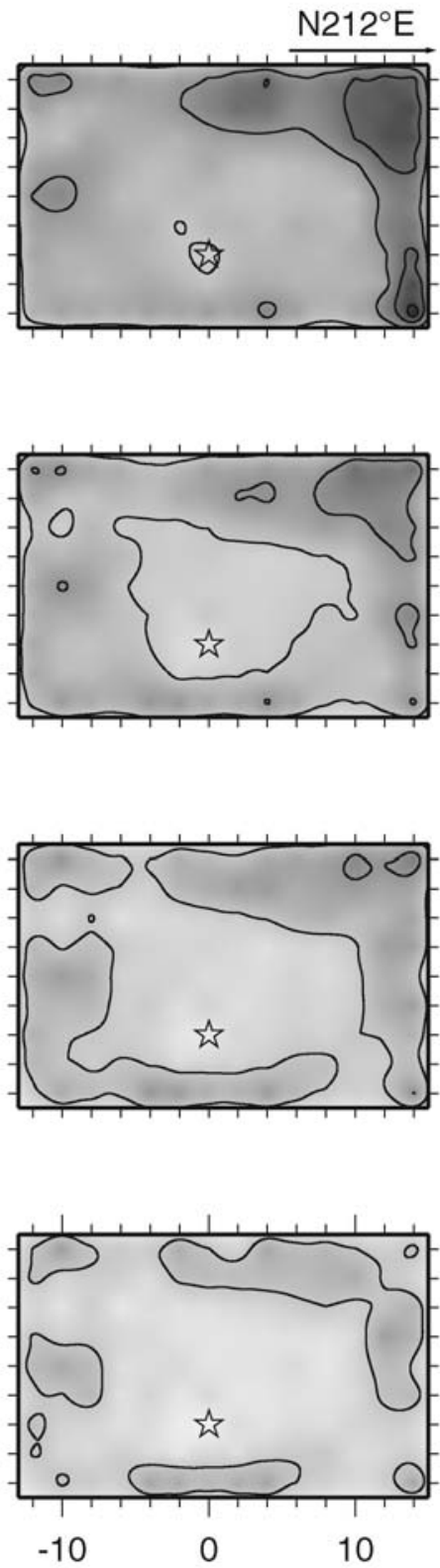

Along Strike $(\mathrm{km})$

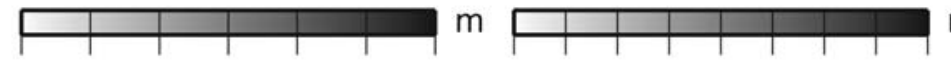

$\begin{array}{lllllllll}0.0 & 0.7 & 1.4 & 2.1 & 2.8 & 3.5 & 4.2 & 0.00 .30 .60 .91 .21 .51 .82 .12 .4\end{array}$

$\mathrm{m}$

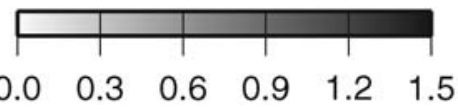

Figure 9. (a) The average slip amount of 200 models obtained with 200 data subsets, (b) the standard deviation, and (c) the coefficient of variance. $N_{s}$ is the number of stations included in the subset.

of broadband strong ground motions using the empirical Green's function method. Their source model comprised two asperities, and their estimations of the stress drop on the asperities are 7 and $20 \mathrm{MPa}$, respectively. In Figure 13, the deeper asperity at the hypocenter has an especially high stress drop. The higher stress drop produces a large slip velocity, and the resulting near-source ground motions tend to be large. This feature is consistent with the conclusion of
Kagawa et al. (2004). The relatively slow rupture propagation velocity is also important to assess the rupture dynamics of this earthquake. Although the multiple-time-window method has some drawbacks in determining the precise rupture velocity, if the relatively slow rupture propagation actually occurs, then the fracture energy of this high-angle dipping fault might be large and the rupture might not propagate smoothly. This might occur because this reverse fault 


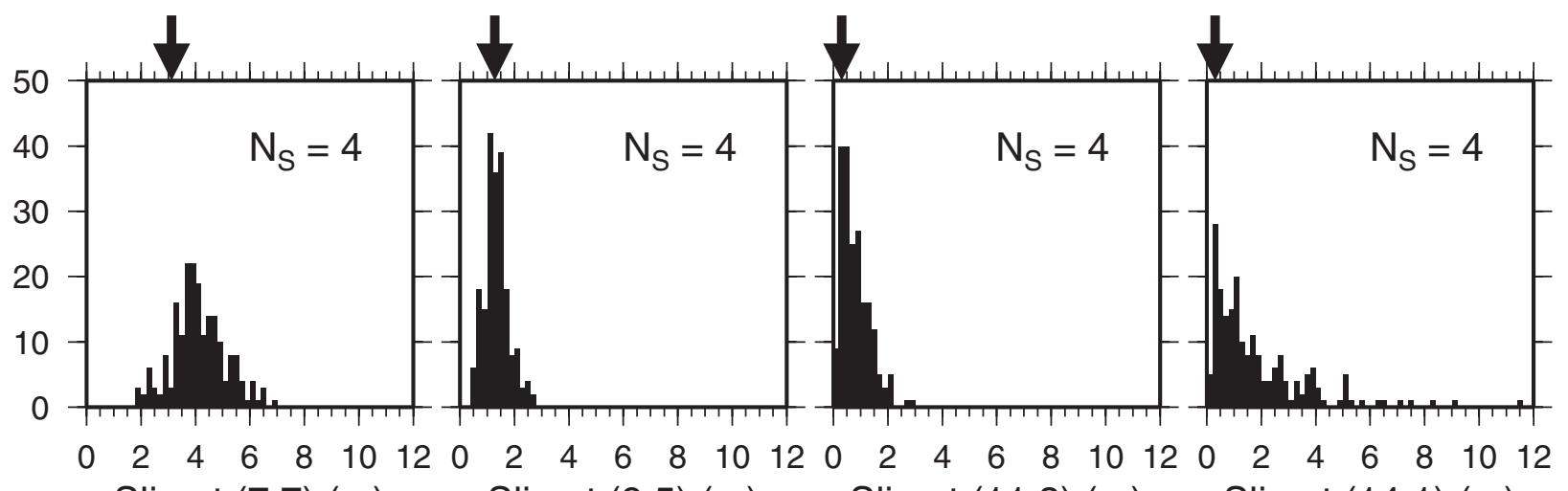

Slip at $(7,7)(m) \quad$ Slip at $(9,5)(m) \quad$ Slip at $(11,3)(m) \quad$ Slip at $(14,1)(m)$

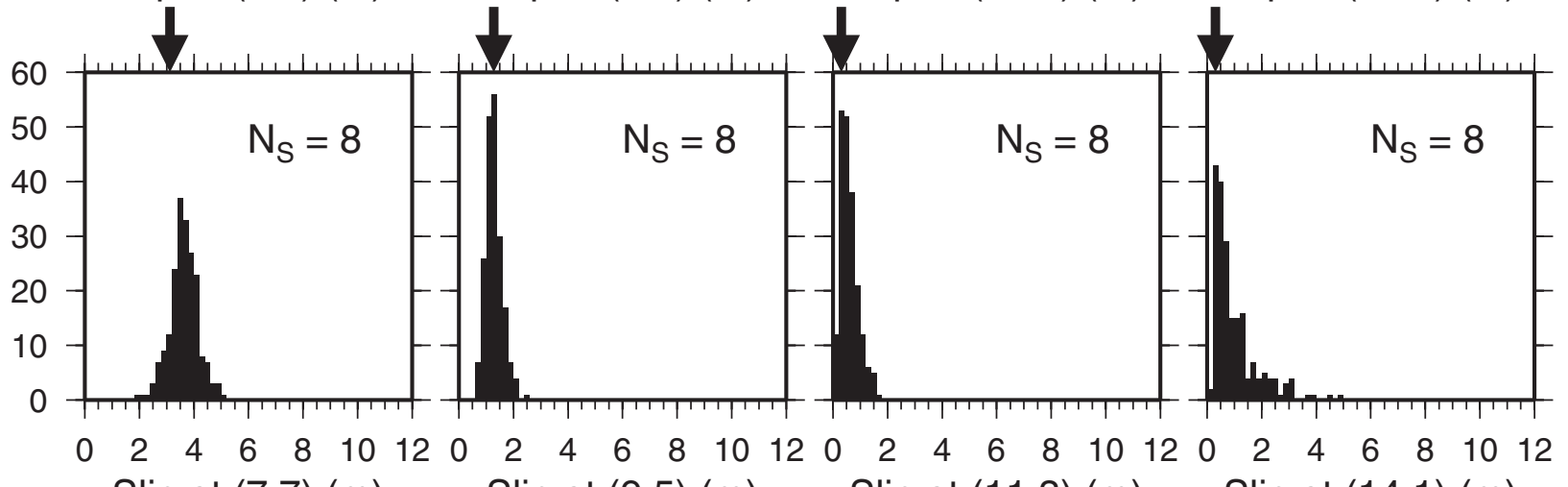

Slip at $(7,7)(m) \quad$ Slip at $(9,5)(m) \quad$ Slip at $(11,3)(m) \quad$ Slip at $(14,1)(m)$

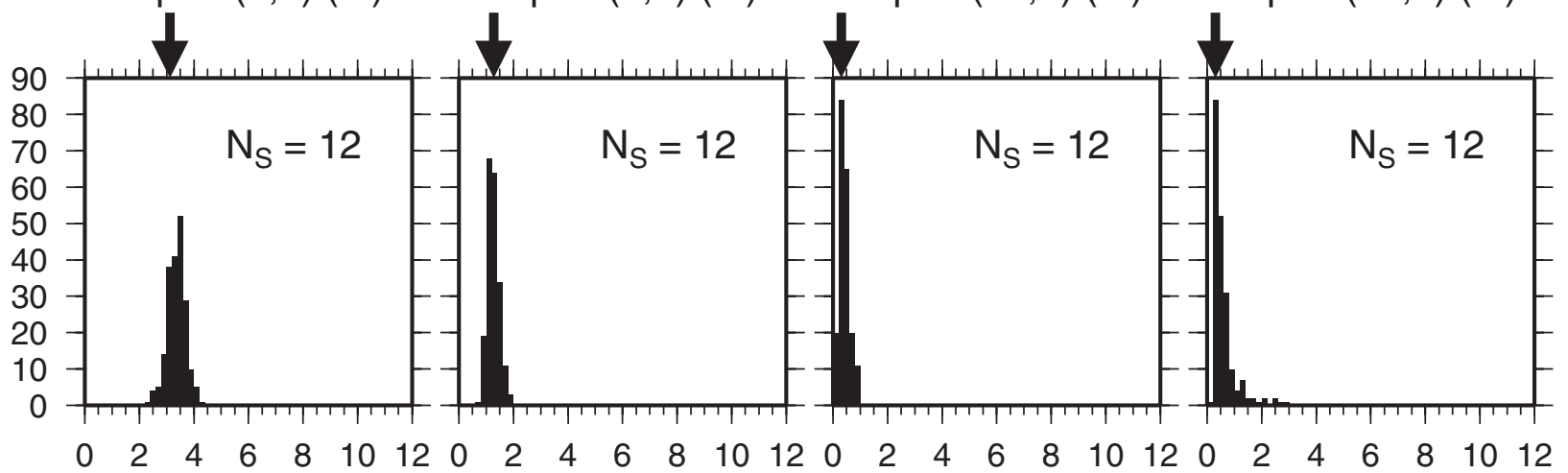

Slip at $(7,7)(m) \quad$ Slip at $(9,5)(m) \quad$ Slip at $(11,3)(m) \quad$ Slip at $(14,1)(m)$

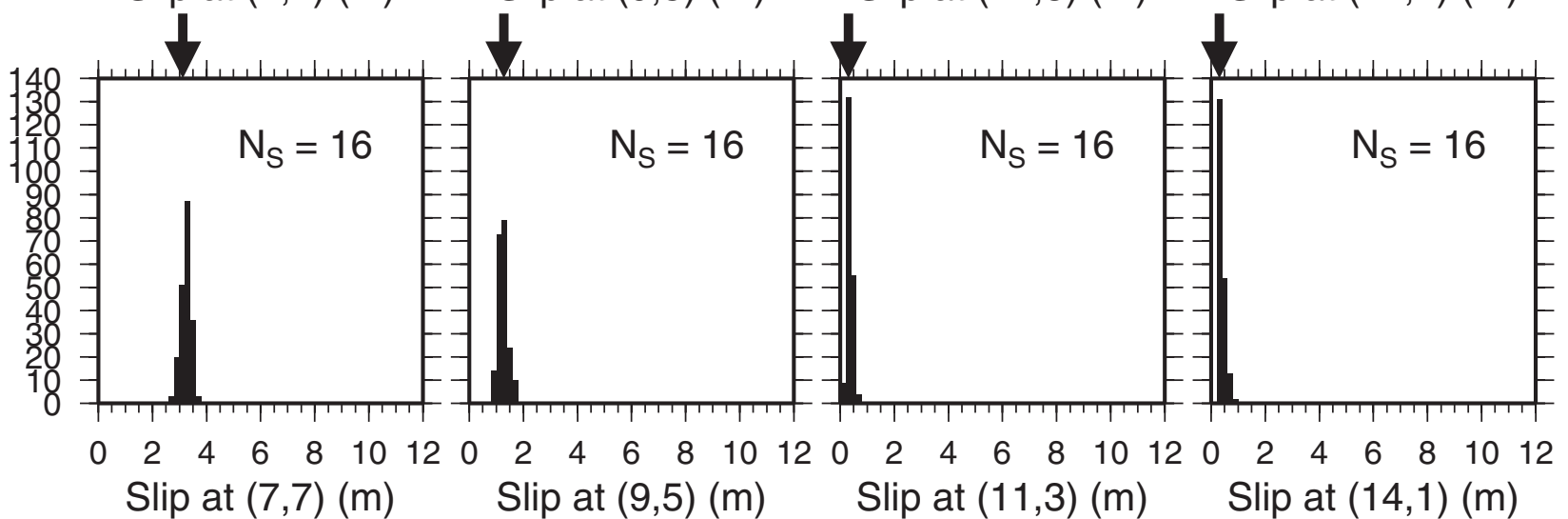

Figure 10. Histograms of slip amount at four subfaults obtained from the 200 inversions for each $N_{s}$. The arrow indicates the slip amount of the reference source model. 
(a)

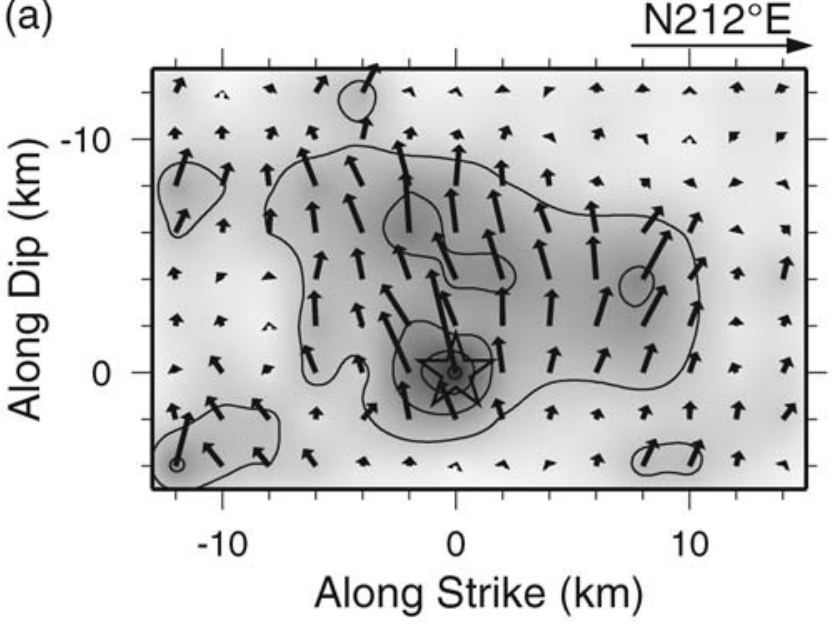

(b)

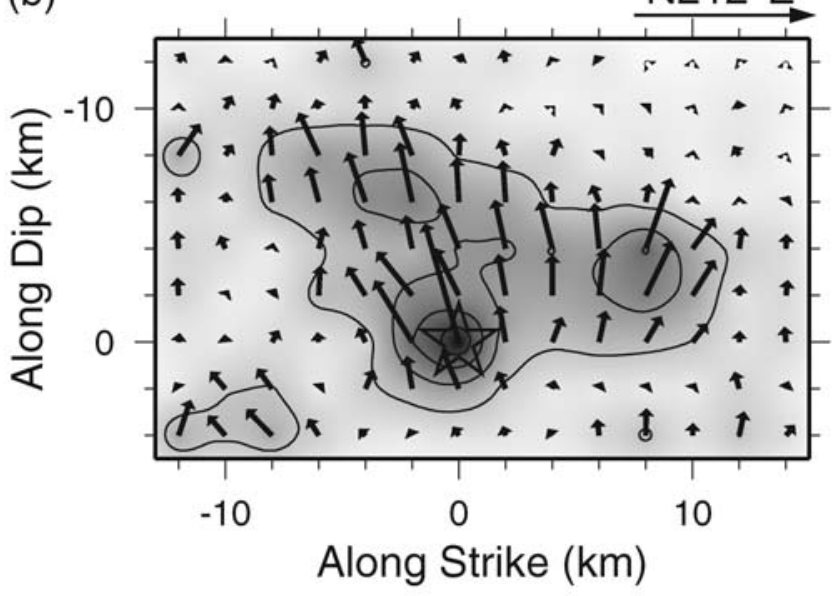

(c)

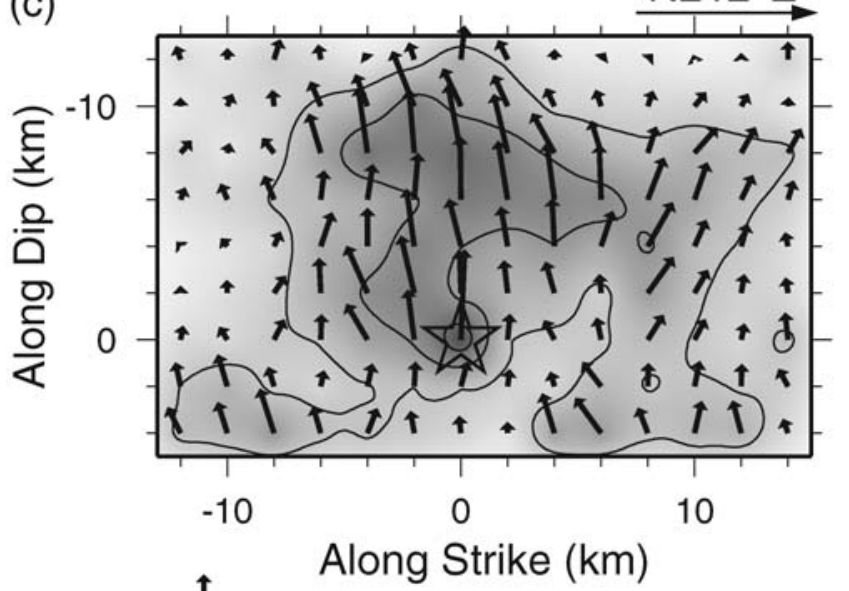

$3 \mathrm{~m}$

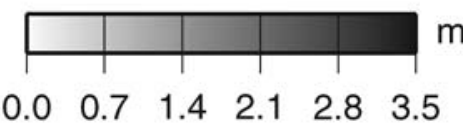

Figure 11. (a) Final slip distribution obtained from the $S$-wave inversion (same as Fig. 5). (b) Final slip distribution obtained from the $P$ - and $S$-wave inversion. The contour interval is $0.7 \mathrm{~m}$. (c) Final slip distribution obtained from the inversion using a single velocity structure model. The notations are the same as in Figure 5. with a steep dip is formed by the reactivation of the normal fault. Fully dynamic rupture modeling might give us more insight on the relationship between the heterogeneous rupture process and the ground-motion generation process, but it might be beyond of the scope of this study.

The kinematic source models of the 2004 Chuetsu earthquake were also estimated using strong ground motions by Hikima and Koketsu (2005), Honda et al. (2005), and Miyazawa et al. (2005). Although these studies used a velocity structure model, a fault plane model, and a data set that differ from those used in this study, the models also have a large slip in the vicinity of the hypocenter, similar to the model obtained in this study. Miyazawa et al. (2005) used six stations of K-NET and KiK-net and a uniform onedimensional velocity structure model obtained from the Joint Hypocenter Determination relocation by Shibutani et al. (2005). Honda et al. (2005) used nine stations of K-NET and KiK-net and three one-dimensional velocity structure models. Hikima and Koketsu (2005) used 11 KiK-net stations, and their velocity structure model depends on each station. The detail in the inversion techniques employed also differed from each other (in terms of the target frequency range, wave type, fault plane model, smoothing constraints, etc.). Because of these differences, the detailed characteristics of the resulting source models might differ. However, the main feature of the source model obtained in this study is similar to that of these source models. This was expected from the results of the test explained in the previous section. This study uses a large number of strong-motion stations, which are uniformly distributed within a radius of $50 \mathrm{~km}$ from the epicenter, and well-calibrated Green's functions, and the source model obtained in this study could explain the observed waveforms at many locations in and around the near-source region. The stability in locating asperities is also confirmed during the jackknife resampling test.

\section{Conclusions}

The spatial and temporal rupture process of the 2004 Chuetsu, mid-Niigata prefecture, Japan, earthquake was estimated in detail by kinematic waveform inversion using dense strong-motion data and well-calibrated Green's functions. In order to calibrate the Green's functions, the velocity structure for each station was modeled using aftershock records and the GA technique. The estimated one-dimensional velocity structures could approximate the wave propagation characteristics of these stations and were successful in simulating the aftershock waveforms. The estimated bedrock depth for each station spatially varies from 0.5 to $7.7 \mathrm{~km}$. The obtained source model of the mainshock shows that the rupture originated from the deeper part of the fault and propagated toward the up-dip and southwest directions. The slip near the ground surface is small, and large slip and high moment rate are observed in and around the hypocenter. In this region, a relatively large stress drop was observed. From two kinds of tests on the effect of the data set, the stability of the 


\section{EW}

NS

UD

EW

Obs.

Syn.

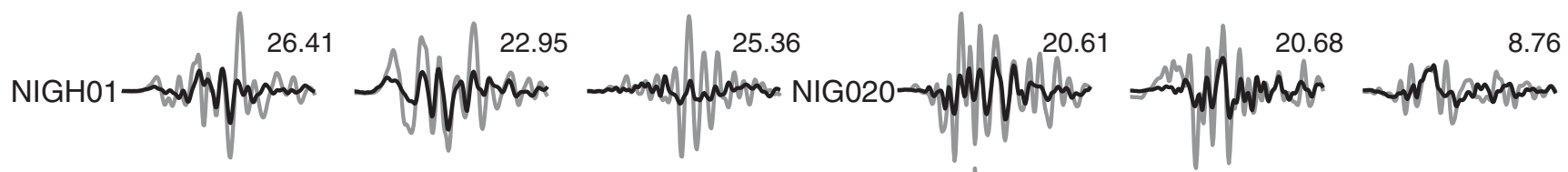

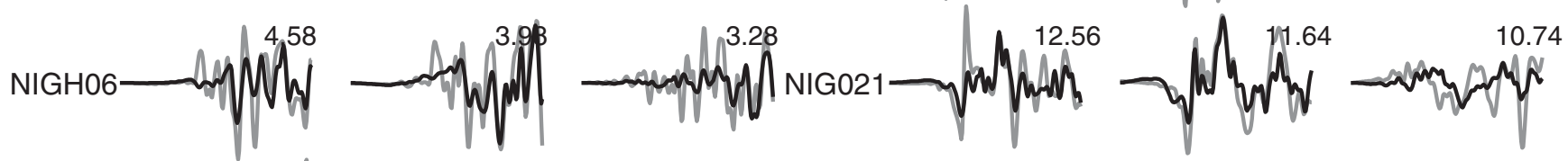

NIGH09-aCWWW

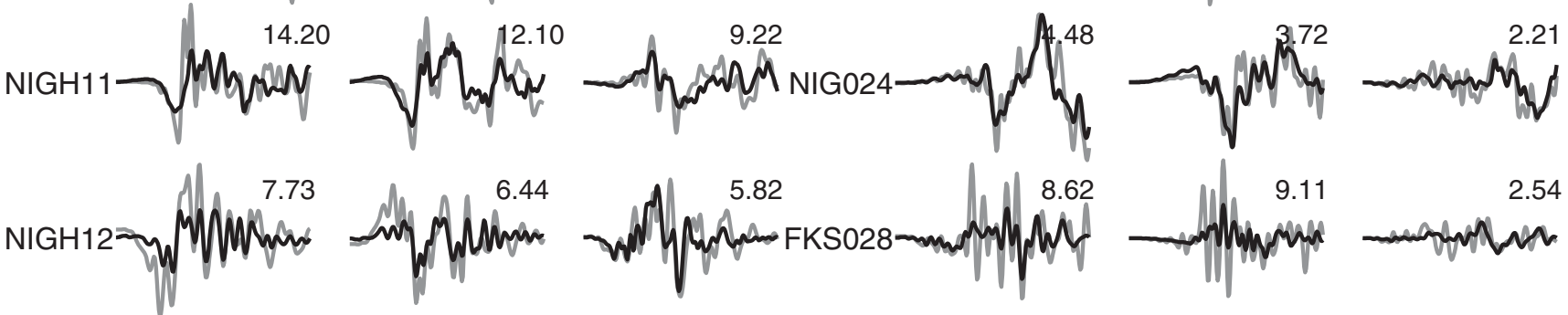

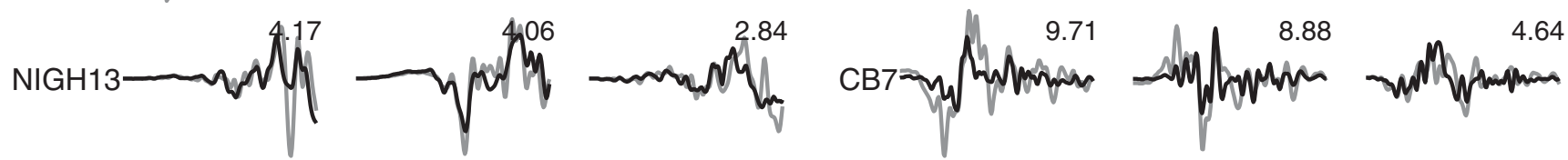

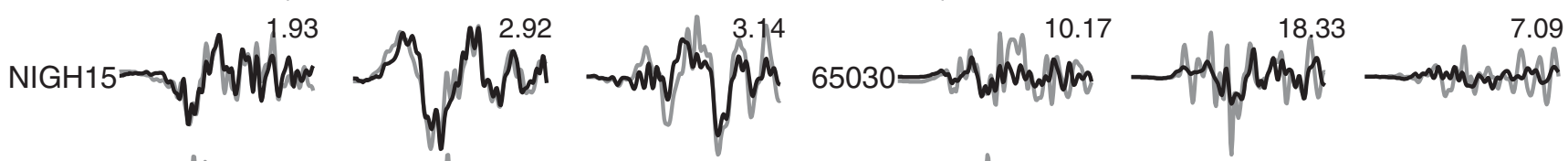

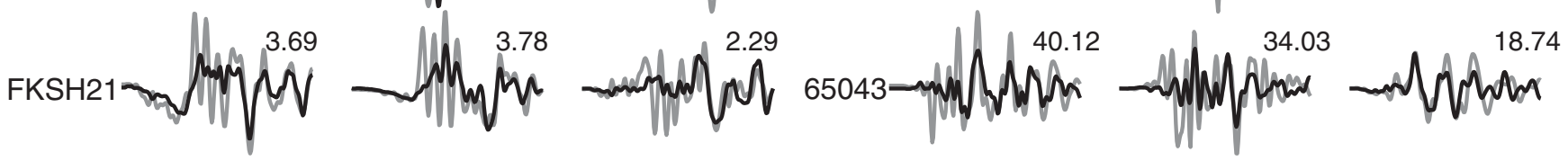

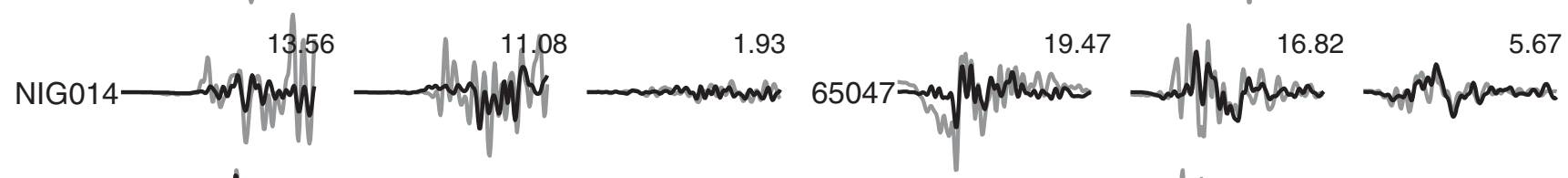

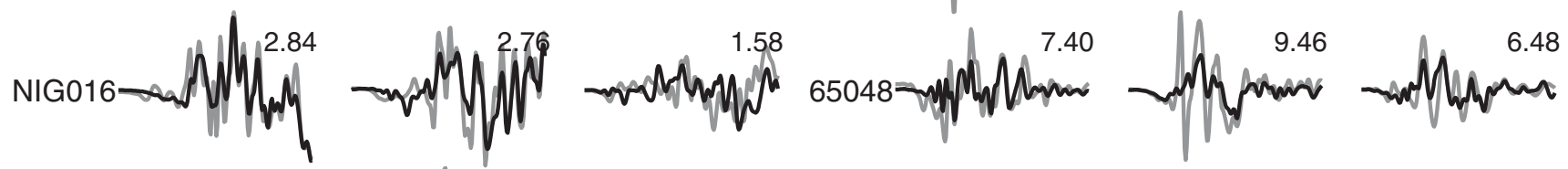

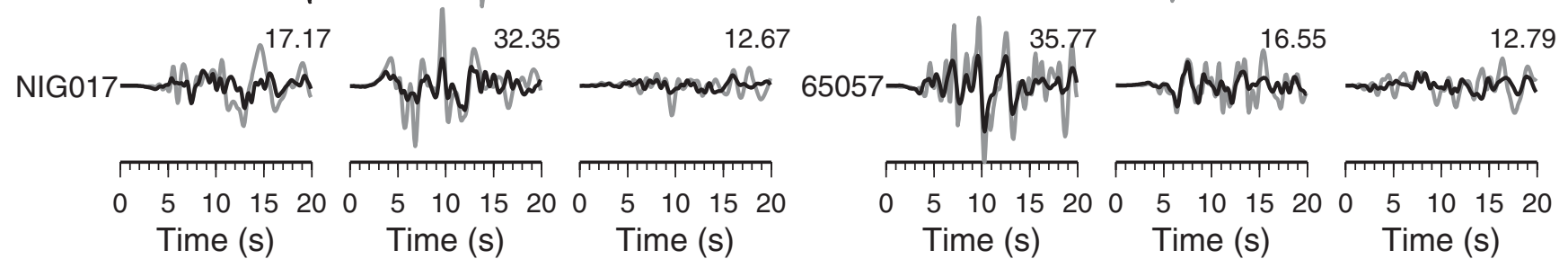

Figure 12. Comparison between observed velocity waveforms (gray line) and synthesized velocity waveforms (solid black line) obtained from the $P$ - and $S$-wave inversion. The notations are the same as in Figure 6. 

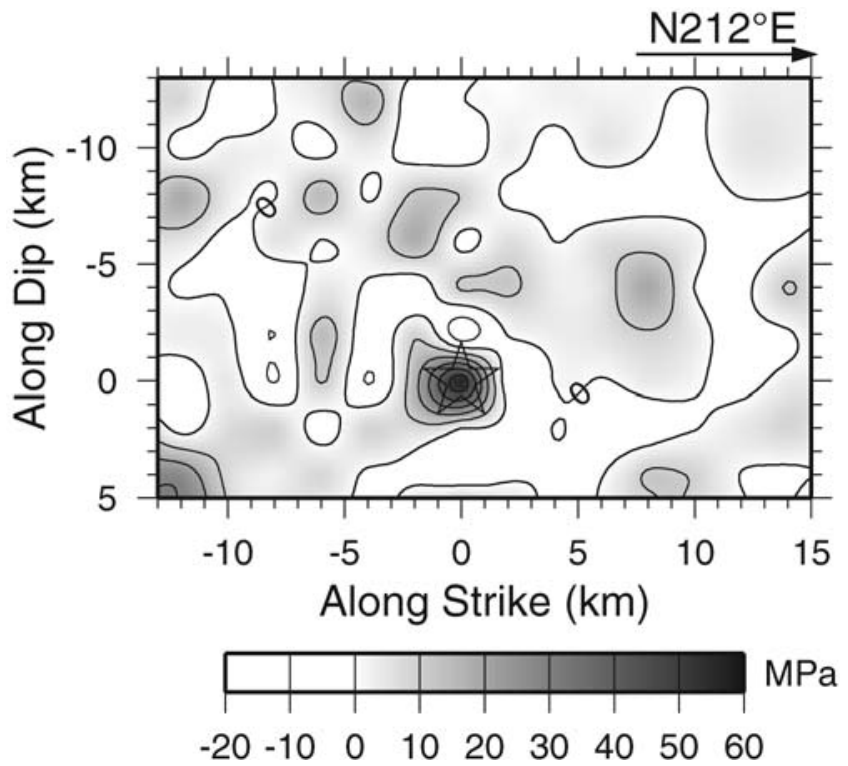

Figure 13. Spatial distribution of the static stress drop on the fault obtained from the final slip distribution. The open star indicates the hypocenter. The contour interval is $10 \mathrm{MPa}$.

source model obtained in this study is examined. The first test examined the effects of the number of available stations on the solution, and the second test examined how the difference in the target waveform type affects the solution. The number of stations affects the variation of slip amount. The underground structure is laterally heterogeneous in the target area; therefore, the use of more than 12 stations is desirable to retrieve a stable source model for the 2004 Chuetsu earthquake. The source model obtained only from the $S$-wave part of ground motions is quite similar to that obtained from the $P$ and $S$ waves. The $S$-wave inversion has a resolution comparable to the simultaneous inversion of $P$ and $S$ waves. Such a comparison is only possible when the number of stations is sufficient and the Green's functions are well calibrated.

\section{Data and Resources}

K-NET and KiK-net data can be obtained from the National Institute for Earth Science and Disaster Prevention at www.kyoshin.bosai.go.jp (last accessed August 2008). Strong-motion data of JMA and Niigata Prefecture Government were collected from the Japan Meteorological Business Support Center by CD-ROM. The F-net moment tensor catalog was searched using www.fnet.bosai.go.jp/fnet/ (last accessed August 2008). The "Active Fault Shape File" by Nakata and Imaizumi (2002) was also used (product serial number: DAFM1483). Most of figures were drawn using the Generic Mapping Tools (Wessel and Smith, 1998).

\section{Acknowledgments}

We sincerely thank Aitaro Kato, Tomomi Okada, and Takuo Shibutani for permitting us to use their original hypocenter information. The discussions with Ralph Archuleta and Hiroe Miyake were very helpful in de- veloping this study. The comments from two anonymous reviewers and Associate Editor Cezar Trifu were helpful in improving the manuscript. The work is supported by a Grant-in-Aid for Young Scientists (Start-Up) No. 19810008 and a Grant-in-Aid for Scientific Research (B) No. 20310105 from the Japan Society for Promotion of Science (JSPS). K. A. was supported by the JSPS Research Fellowships for Young Scientists.

\section{References}

Akaike, H. (1980). Likelihood and the Bayes procedure, in Bayesian Statistics, J. M. Bernardo, M. H. DeGroot, D. V. Lindley and A. F. M. Smith (Editors), University Press, Valencia, Spain, 143-166.

Aoi, S., K. Obara, S. Hori, K. Kasahara, and Y. Okada (2000). New strongmotion observation network: KiK-net, Eos Trans. AGU 81, F863.

Asano, K., T. Iwata, and K. Irikura (2005). Estimation of source rupture process and strong ground motion simulation of the 2002 Denali, Alaska, earthquake, Bull. Seismol. Soc. Am. 95, 1701-1715.

Beresnev, I. A. (2003). Uncertainties in finite-fault slip inversions: to what extent to believe? (a critical review), Bull. Seismol. Soc. Am. 93, 2445-2458.

Bouchon, M. (1981). A simple method to calculate Green's functions for elastic layered media, Bull. Seismol. Soc. Am. 71, 959-971.

Carroll, D. L. (1996). Genetic algorithms and optimizing chemical oxygeniodine lasers, in Developments in Theoretical and Applied Mechanics, H. B. Wilson, R. C. Batra, C. W. Bert, A. M. J. Davis, R. A. Schapery, D. S. Stewart and F. F. Swinson (Editors), University of Alabama, School of Engineering, Tuscaloosa, Alabama, Vol. 18, 411-424.

Custódio, S., P. Liu, and R. J. Archuleta (2005). The $2004 M_{\mathrm{w}} 6.0$ Parkfield, California, earthquake: inversion of near-source ground motion using multiple data sets, Geophys. Res. Lett. 32, L23312, doi 10.1029/ 2005 GL024417.

Efron, B. (1982). The Jackknife, the Bootstrap and Other Resampling Plans, Society for Industrial and Applied Mathematics, Philadelphia, 92 pp.

Geller, R. J. (1976). Scaling relations for earthquake source parameters and magnitudes, Bull. Seismol. Soc. Am. 66, 1501-1523.

Graves, R. W., and D. J. Wald (2001). Resolution analysis of finite fault source inversion using one- and three-dimensional Green's functions, 1, strong motions, J. Geophys. Res. 106, 8745-8766.

Hartzell, S. H., and T. H. Heaton (1983). Inversion of strong ground motion and teleseismic waveform data for the fault rupture history of the 1979 Imperial Valley, California, earthquake, Bull. Seismol. Soc. Am. 73, $1553-1583$.

Hikima, K., and K. Koketsu (2005). Rupture process of the 2004 Chuetsu (mid-Niigata prefecture) earthquake, Japan: a series of events in a complex fault system, Geophys. Res. Lett. 32, L18303, doi 10.1029/ 2005 GL023588.

Holland, J. H. (1975). Adaptation in Natural and Artificial Systems, University of Michigan Press, Ann Arbor, 183 pp.

Honda, R., S. Aoi, N. Morikawa, H. Sekiguchi, T. Kunugi, and H. Fujiwara (2005). Ground motion and rupture process of the 2004 mid Niigata prefecture earthquake obtained from strong motion data of K-NET and KiK-net, Earth Planets Space 57, 527-532.

Ichinose, G. A., H. K. Thio, P. G. Somerville, T. Sato, and T. Ishii (2003). Rupture process of the 1944 Tonankai earthquake $\left(M_{\mathrm{S}} 8.1\right)$ from the inversion of teleseismic and regional seismograms, J. Geophys. Res. 108, 2497, doi 10.1029/2003JB002393.

Iida, M., T. Miyatake, and K. Shimazaki (1988). Optimum strong-motion array geometry for source inversion, Earthq. Eng. Struct. Dyn. 16, $1213-1225$.

Iida, M., T. Miyatake, and K. Shimazaki (1990). Relationship between strong-motion array parameters and the accuracy of source inversion and physical waves, Bull. Seismol. Soc. Am. 80, 1533-1552.

Ikami, A., T. Yoshii, S. Kubota, Y. Sasaki, A. Hasemi, T. Moriya, H. Miyamachi, R. S. Matsu'ura, and K. Wada (1986). A seismic-refraction profile in and around Nagano Prefecture, central Japan, J. Phys. Earth 34, 457-474. 
Kagawa, T., K. Irikura, and P. G. Somerville (2004). Differences in ground motion and fault rupture process between the surface and buried rupture earthquakes, Earth Planets Space 56, 3-14.

Kamae, K., T. Ikeda, and S. Miwa (2005). Source model composed of asperities for the 2004 Mid Niigata Prefecture, Japan, earthquake $\left(M_{\mathrm{JMA}}=6.8\right)$ by the forward modeling using the empirical Green's function method, Earth Planets Space 57, 533-538.

Kato, A., E. Kurashimo, N. Hirata, S. Sakai, T. Iwasaki, and T. Kanazawa (2005). Imaging the source region of the 2004 mid-Niigata prefecture earthquake and the evolution of a seismogenic thrust-related fold, Geophys. Res. Lett. 32, L07307, doi 10.1029/2005GL022366.

Kato, A., S. Sakai, N. Hirata, E. Kurashimo, T. Iidaka, T. Iwasaki, and T. Kanazawa (2006). Imaging the seismic structure and stress field in the source region of the 2004 mid-Niigata prefecture earthquake: structural zones of weakness and seismogenic stress concentration by ductile flow, J. Geophys. Res. 111, B08308, doi 10.1029/2005JB004016.

Kennett, B. L. N., and N. J. Kerry (1979). Seismic waves in a stratified half space, Geophys. J. R. Astr. Soc. 57, 557-583.

Kim, H. Y., and A. Okada (2005). Surface deformations associated with the October 2004 Mid-Niigata earthquake: description and discussion, Earth Planets Space 57, 1093-1102.

Kinoshita, S. (1998). Kyoshin Net (K-NET), Seism. Res. Lett. 69, 309-332.

Koketsu, K., T. Ohno, and Y. Ikegami (2003). Rupture process inversion using 3-D Green's functions: the 1995 Kobe earthquake revisited, Eos Trans. AGU 84, F1109.

Lawson, C. L., and R. J. Hanson (1974). Solving Least Squares Problems, Prentice Hall, New York, 340 pp.

Liu, P., and R. J. Archuleta (2004). A new nonlinear finite fault inversion with three-dimensional Green's functions: application to the 1989 Loma Prieta, California, earthquake, J. Geophys. Res. 109, B02318, doi 10.1029/2003JB002625.

Matsumoto, M., and T. Nishimura (1998). Mersenne Twister: a 623dimensionally equidistributed uniform pseudorandom number generator, ACM Trans. Model. Comput. Simul. 8, 3-30.

Miyazawa, M., J. Mori, Y. Iio, T. Shibutani, S. Matsumoto, H. Katao, S. Ohmi, and K. Nishigami (2005). Triggering sequence of large aftershocks of the mid Niigata prefecture, Japan earthquake in 2004 by static stress changes, Earth Planets Space 57, 1109-1113.

Mori, H., and T. Iwata (2006). Nonlinear site amplification characteristics at strong motion stations during the 2004 Niigata-Ken-Chuetsu earthquake, Japan, in the Proceedings of the 19th KKCNN (Korean Advanced Institute of Science and Technology, Kyoto University, Chulalongkorn University, National Taiwan University, and National University of Singapore) Symposium on Civil Engineering, Kyoto, Japan, 113-116.

Mori, J., and P. Somerville (2006). Seismology and strong ground motions in the 2004 Niigata Ken Chuetsu, Japan, earthquake, Earthq. Spectra 22, S9-S21.

Nakata, T., and T. Imaizumi (2002). Digital Active Fault Map of Japan, University of Tokyo Press, Tokyo, 60 pp. (with 2 DVD-ROMs) (in Japanese).

Nishigami, K. (2006). Crustal heterogeneity in the source region of the 2004 mid Niigata prefecture earthquake: inversion analysis of coda envelopes, Pure Appl. Geophys. 163, 601-616.

Okada, T., N. Umino, T. Matsuzawa, J. Nakajima, N. Uchida, T. Nakayama, S. Hirahara, T. Sato, S. Hori, T. Kono, Y. Yabe, K. Ariyoshi, S.
Gamage, J. Shimizu, J. Suganomata, S. Kita, S. Yui, M. Arao, S. Hondo, T. Mizukami, H. Tsushima, T. Yaginuma, A. Hasegawa, Y. Asano, H. Zhang, and C. Thurber (2005). Aftershock distribution and 3D seismic velocity structure in and around the focal area of the 2004 mid Niigata prefecture earthquake obtained by applying double-difference tomography to dense temporary seismic network data, Earth Planets Space 57, 435-440.

Okada, T., T. Yaginuma, N. Umino, T. Matsuzawa, A. Hasegawa, H. Zhang, and C. H. Thurber (2006). Detailed imaging of the fault planes of the 2004 Niigata-Chuetsu, central Japan, earthquake sequence by doubledifference tomography, Earth Planet. Sci. Lett. 244, 32-43.

Ripperger, J., and P. M. Mai (2004). Fast computation of static stress changes on 2D faults from final slip distributions, Geophys. Res. Lett. 31, L18610, doi 10.1029/2004GL020594.

Saraó, A., S. Das, and P. Suhadolc (1998). Effect of non-uniform station coverage on the inversion for earthquake rupture history for a Haskelltype source model, J. Seism. 2, 1-25.

Sato, H. (1994). The relationship between late Cenozoic tectonic events and stress field and basin development in northeastern Japan, J. Geophys. Res. 99, 22,261-22,274.

Sekiguchi, H., K. Irikura, and T. Iwata (2000). Fault geometry in the rupture termination of the 1995 Hyogo-ken Nanbu earthquake, Bull. Seismol. Soc. Am. 90, 117-133.

Sen, M. K., and P. L. Stoffa (1991). Nonlinear one-dimensional seismic waveform inversion using simulated annealing, Geophys. 56, $1624-1638$

Shibutani, T., Y. Iio, S. Matsumoto, H. Katao, T. Matsuhima, S. Ohmi, F. Takeuchi, K. Uehira, K. Nishigami, B. Enescu, I. Hirose, Y. Kano, Y. Kohno, M. Korenaga, Y. Mamada, M. Miyazawa, K. Tatsumi, T. Ueno, H. Wada, and Y. Yukutake (2005). Aftershock distribution of the 2004 mid Niigata prefecture earthquake derived from a combined analysis of temporary online observations and permanent observations, Earth Planets Space 57, 545-549.

Smith, W. H. F., and P. Wessel (1990). Gridding with continuous curvature splines in tension, Geophysics 55, 293-305.

Tokimatsu, K., and T. Sekiguchi (2006). Effects of nonlinear properties of surface soils on strong ground motions recorded in Ojiya during 2004 Mid Niigata Prefecture earthquake, Soils and Foundations 46, $765-775$.

Wessel, P., and W. H. F. Smith (1998). New, improved version of Generic Mapping Tools released, Eos Trans. AGU 79, 579.

Yamanaka, H., K. Motoki, S. Fukumoto, T. Takahashi, N. Yamada, and K. Asano (2005). Estimation of local site effects in Ojiya City using aftershock records of the 2004 mid Niigata prefecture earthquake and microtremors, Earth Planets Space 57, 539-544.

Disaster Prevention Research Institute

Kyoto University

Gokasho, Uji, Kyoto 611-0011, Japan

k-asano@egmdpri01.dpri.kyoto-u.ac.jp

iwata@egmdpri01.dpri.kyoto-u.ac.jp

Manuscript received 5 December 2006 